PAULO CÉSAR NUNES GIL

Uso da maltodextrina na substituição do amido em dieta para eqüinos

Pirassununga 


\section{Uso da maltodextrina na substituição do amido em dieta para eqüinos}

Dissertação de apresentada ao Programa de PósGraduação em Nutrição e Produção Animal da Faculdade de Medicina Veterinária e Zootecnia da Universidade de São Paulo para obtenção do título de Mestre em Ciências

Departamento:

Nutrição e Produção Animal

Área de concentração:

Nutrição e Produção Animal

Orientador:

Prof. Dr. Alexandre Augusto de Oliveira Gobesso

Pirassununga 
Autorizo a reprodução parcial ou total desta obra, para fins acadêmicos, desde que citada a fonte.

DADOS INTERNACIONAIS DE CATALOGAÇÃO-NA-PUBLICAÇÃO

(Biblioteca Virginie Buff D'Ápice da Faculdade de Medicina Veterinária e Zootecnia da Universidade de São Paulo)

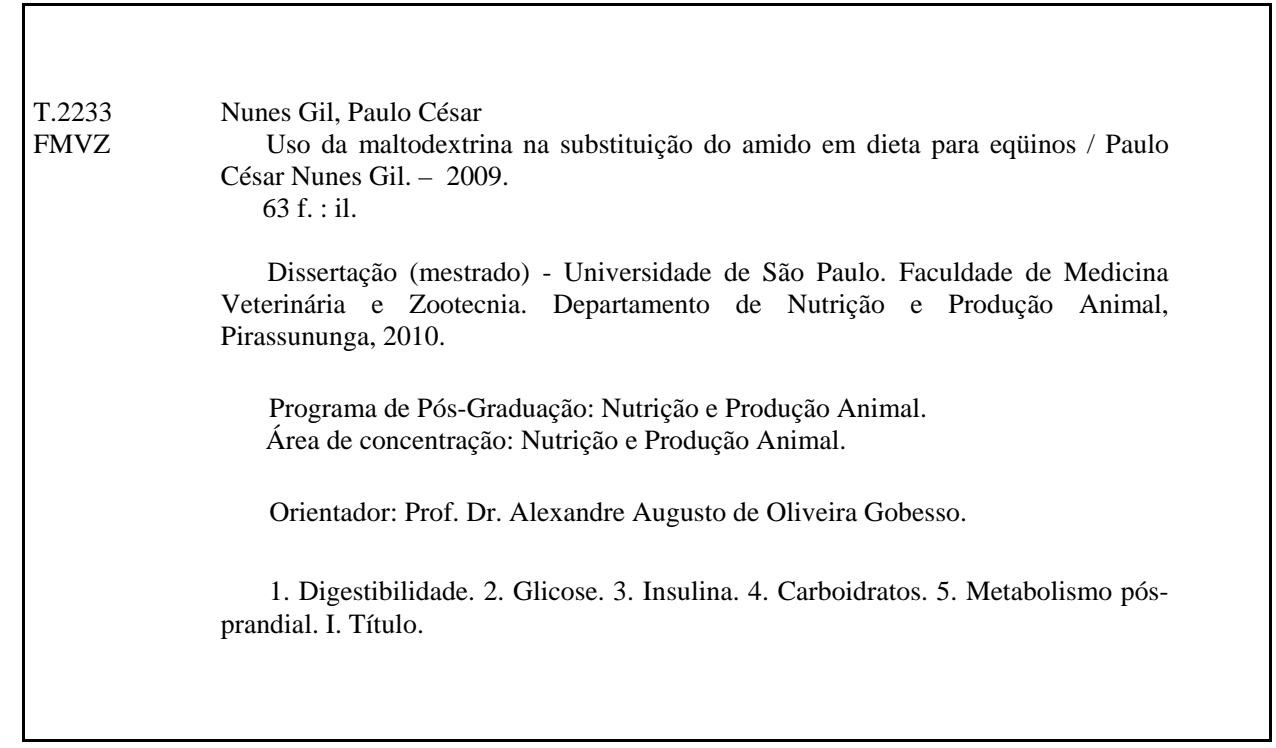




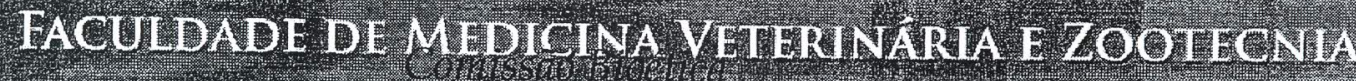

\section{CERTIFICADO}

Certificamos que o Projeto intitulado "Uso da maltodextrina na substituição do amido em dieta para equinos", protocolado sob o $n^{\circ} 1626 / 2009$, utilizando 04 (quatro) mestiços, sob a responsabilidade do Prof. Dr. Alexandre Augusto de Oliveira Gobesso, está de acordo com os princípios éticos de experimentação animal da Comissão de Bioética da Faculdade de Medicina Veterinária e Zootecnia da Universidade de São Paulo e foi aprovado em reunião de 20/05/09.

We certify that the Research "Maltdextrin in substitution of starch in equine diet", protocol number 1626/2009, utilizing 04 (four) equines, under the Prof. Dr. Alexandre Augusto de Oliveira Gobesso, agree with Ethical Principles in Animal Research adopted by Bioethic Commission of the School of Veterinary Medicine and Animal Science of University of São Paulo and was approved in the meeting of day $05 / 20 / 09$.

São Paulo, 21 de maio de 2009

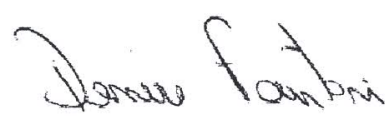

Profa Dra Denise Tabacchi Fantoni

Presidente da Comissão de Bioética FMVZ/USP 


\section{FOLHA DE AVALIAÇÃO}

NOME: NUNES GIL, Paulo César

Titulo: Uso da maltodextrina na substituição do amido em dieta para eqüinos

Dissertação apresentada ao Programa de PósGraduação em Nutrição e Produção Animal da Faculdade de Medicina Veterinária e Zootecnia da Universidade de São Paulo para obtenção do título de Mestre em Ciências

DATA:

BANCA EXAMINADORA

Prof. Dr.

Assinatura:

Prof. Dr.

Assinatura:

Prof. Dr.

Assinatura:
Instituição:

Julgamento:

Instituição:

Julgamento: 


\section{DEDICATÓRIA}

Aos meus pais Jesus e Vanderci pelo empenho e dedicação em minha educação.

À minha esposa Ana Cecília pela paciência e compreensão.

Às filhas Paula e Carolina que são motivos de orgulho para mim.

Às minhas irmãs Cibele e Simone por acreditarem que iria concluir.

Aos meus avós Roque(in memorian), Felicidade(in memorian), Adalgizo(in memorian) e Júlia(in memorian), que são minhas referências em honestidade e trabalho. 


\section{AGRADECIMENTOS}

À Universidade de São Paulo, à Faculdade de Medicina Veterinária e Zootecnia e ao Departamento de Nutrição e Produção Animal pela oportunidade da realização deste curso;

À FAPESP pelo financiamento deste projeto de estudo;

À empresa Ouro Fino Saúde Animal por acreditar em meu trabalho e me conceder o tempo e todo o recurso necessário para a execução deste projeto em minha vida; especialmente ao Sr Norival Bonamichi, Sr Jardel Massari e ao Dr Carlos Henrique Henrique pela compreensão e confiança em todos os momentos deste experimento;

Ao meu orientador e amigo, Prof. Dr. Alexandre Augusto de Oliveira Gobesso, pela orientação, apoio incondicional, e seu grande dissernimento no direcionamento em todas as etapas deste experimento.

Aos professores do Departamento de Nutrição e Produção Animal da Faculdade de Medicina Veterinária e Zootecnia da Universidade de São Paulo pelos ensinamentos transmitidos e antes disto, pelo exemplo profissional.

Aos colegas de curso Henry, Yassanã, Aline, Yara, Fernanda,Waleska e Jefferson, que colaboraram ativamente em todas as etapas deste curso e me fizeram relembrar o conceito verdadeiro da palavra amigo;

Aos funcionários do Setor de Equideocultura, Srs Valdir e Maico pelo auxilio e convívio durante o experimento;

À empresa Corn Products pelo fornecimento de parte das matérias-primas para a execução deste experimento;

Aos animais Amazonas, Avelã, Avenca e Atenas, pois através deles foi possível este estudo. 
“Nunca nos tornaremos matemáticos ainda que a nossa memória possua todas as demonstrações feitas por outros, se nosso espírito não for capaz de resolver toda espécie de problemas;

Nunca nos tornaremos filósofos pelo simples fato de termos lido todos os argumentos de Platão e Aristóteles, mas sem podermos emitir um sólido juízo sobre o que nos é proposto.

Deste modo, com efeito, é como se tivéssemos aprendido não ciências, mas histórias”.

René Descartes(Regras para Direção do Espírito)

Olhai desprezadores, maravilhai-vos e desaparecei!

Porque eu vou fazer, ainda em vossos dias, uma obra tal que não acreditaríeis, se alguém vo-la narrase!"

Atos dos Apóstolos 


\section{RESUMO}

NUNES GIL, P. C. Uso da maltodextrina na substituição do amido em dieta para eqüinos. [Usefull of maltodextrina in replace of starch in equine diets]. 2009 63f. Dissertação (Mestrado em Ciências) - Faculdade de Medicina Veterinária e Zootecnia, Universidade de São Paulo, Pirassununga, 2009.

O objetivo deste estudo foi determinar os efeitos da suplementação com maltodextrina, na substituição do amido na dieta de eqüinos avaliando a digestibilidade aparente total da matéria seca e nutriente e as diferenças nas respostas glicêmicas e insulinêmicas das dietas determinadas. Foram utilizados quatro eqüinos fêmeas com idade aproximada de 30 meses, peso médio de $400 \mathrm{~kg}$, pertencentes ao rebanho da USP. Os animais foram imunizados contra tétano, vermifugados e pulverizados contra ectoparasitos. A dieta foi composta por $50 \%$ de concentrado e $50 \%$ de volumoso, formulada para atender as exigências de crescimento e mantença da categoria eqüina utilizada. As dietas continham $50 \%$ de amido no concentrado, substituídas em 33, 66\% e 100\% de maltodextrina. A colheita total de fezes foi feita em um período de 24 horas durante 03 (três) dias, com animais mantidos em baias, com piso de concreto, sem cama. No primeiro dia de colheita de fezes foram realizadas as coletas de sangue em tubos previamente preparados com estabilizantes, a partir da veia jugular, 30 minutos antes, 30 minutos, 90 minutos, 150 minutos, 210 minutos após o fornecimento do concentrado para dosagem de glicose e insulina.Não foi observado efeito linear ou quadrático para os coeficientes de digestibilidade aparente total da matéria seca e de nutriente, no entanto foi observado uma maior coeficiente de digestibilidade aparente total da ração com $100 \%$ de substituição do amido pela maltodextrina no concentrado, para a matéria seca, matéria orgânica, proteína bruta, fibra em detergente neutro e ácido. Em relação as respostas glicêmicas e insulinêmicas foi observado efeito quadrático para a glicose quando se analisou a área abaixo da curva desta variável. Da mesma forma foi observado um comportamento linear para a insulina. Quando se analisou a resposta das variáveis em função do tempo se observou um pico de glicose e insulina entre os tempo de 1,5 a 2 horas pós-alimentação, em relação a glicose a ração com $66 \%$ de substituição apresentou maior pico e a ração com $100 \%$ de substituição apresentou maior pico de insulina. O resultado do uso da maltodextrina sobre a fisiologia digestiva e o comportamento pós-brandial em eqüinos, permite sua inclusão na dieta dos animais.

Palavras-chave: Digestibilidade. Glicose. Insulina. Carboidratos. Metabolismo pós-prandial. 


\begin{abstract}
NUNES GIL, P. C. Usefull of maltodextrina in replace of starch in equine diets. [Uso da maltodextrina na substituição do amido em dieta para eqüinos]. 2009. 63 f. Dissertação (Mestrado em Ciências) - Faculdade de Medicina Veterinária e Zootecnia, Universidade de São Paulo, Pirassununga, 2009.
\end{abstract}

The objective of this study was to determine the effects of supplementation with maltodextrin, the replacement of starch in the diet of horses by evaluating the apparent digestibility of dry matter and nutrient and differences in glycemic responses and insulinemic certain diets. There were four female horses aged approximately 30 months, average weight of $400 \mathrm{~kg}$, belonging to the flock of USP. The animals were immunized against tetanus, wormed and pulverized against ectoparasites. The diet was composed by $50 \%$ concentrate and $50 \%$ forage diet formulated to meet the demands of growth and maintenance of category equine use. The diets contained 50\% starch in the concentrate, replaced in 33, 66 and 100\% of maltodextrin. The total collection of feces was made in a period of 24 hours over 03 (three) days, with animals kept in stalls with concrete floor, without bedding. On the first day of faeces were carried out blood samples in tubes previously prepared with stabilizers from the jugular vein 30 minutes before 30 minutes, 90 minutes, 150 minutes, 210 minutes after delivery of the concentrate to measure glucose and insulin. Were not observed effects linear or quadratic for the coefficients of apparent digestibility of dry matter and nutrient, however it was observed a higher coefficient of apparent digestibility of the ration with $100 \%$ replacement of starch by maltodextrin in concentrated, dry matter, organic matter, crude protein, neutral detergent fiber and acid. For the glycemic responses and insulin levels were observed quadratic effect for glucose when we analyzed the area under the curve of this variable. Similarly, it was observed a linear behavior for insulin. When analyzing their response as a function of time was observed a peak of glucose and insulin between the time of 1.5 to 2 hours post-feeding in relation to glucose diet with $66 \%$ replacement had a higher peak and cooperation with $100 \%$ replacement had a higher peak insulin. The results of maltodextrin use on digestive physiology and its post prandial behavior in equines allow its inclusion in animal diets.

Keywords: Digestibility. Glucose. Insulin. Carbohydrates. Postprandial metabolism. 


\section{LISTA DE TABELAS}

Tabela 1- Composição dos ingredientes e bromatologica dos concentrados experimentais

Tabela 2- Composição dos ingredientes e bromatológica das dietas experimentais

Tabela 3 - Delineamento em quadrado latino para realizado.

Tabela 4- Consumo da ração, feno, concentrado, maltodextrina e nutrientes em função das dietas experimentais

Tabela 5- Medias, coeficientes de variação (CV) dos coeficientes de digestibilidade aparente total em função das rações experimentais

Tabela 06- Medias, coeficientes de variação (CV) da área abaixa da curva (AAC) em função das rações experimentais

Tabela 7- Media, coeficiente de variação (CV), do nível de glicose sanguínea em função das rações experimentais

Tabela 8- Médias das concentrações plasmáticas de glicose e insulina, em função dos tempos de colheitas, de acordo com as dietas experimentais. 


\section{LISTA DE FIGURAS}

Figura 1 - Coeficientes de digestibilidade da matéria seca e da matéria orgânica em função das rações experimentais.

Figura 2 - Coeficientes de digestibilidade da proteína bruta em função das rações experimentais

Figura 3 - Coeficientes de digestibilidade da fibra em detergente neutro e fibra em detergente ácido em função das rações experimentais

Figura 4 - Coeficientes de digestibilidade do extrato etéreo, fibra bruta e matéria mineral em função das rações experimentais....

Figura 5 - Coeficientes de digestibilidade do amido, em função das rações experimentais.

Figura 6 - Área abaixo da curva (AAC) dos níveis estimatimados e observados de glicose plamática, em função das dietas experimentais

Figura 7- Concentração plasmática de glicose em função do tempo de acordo com as dietas experimentais.

Figura 8- Concentração plasmática de insulina em função do tempo de acordo com as dietas experimentais. 


$\begin{array}{ll}\text { AAC } & \text { ÁREA ABAIXO DA CURVA } \\ \text { MS } & \text { MATERIA SECA } \\ \text { CHO } & \text { CARBOIDRATO } \\ \text { FDN } & \text { FIBRA EM DETERGENTE NEUTRO } \\ \text { FDA } & \text { FIBRA EM DETERGENTE ÁCIDO } \\ \text { CNF } & \text { CARBOIDRATO NÃO FIBROSO } \\ \text { EE } & \text { EXTRATO ETÉREO }\end{array}$




\section{SUMÁRIO}

1 INTRODUÇÃO ...........................................................................................................13

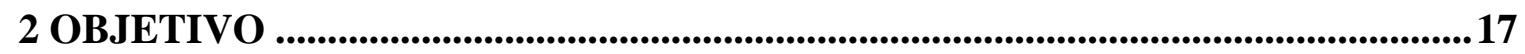

3REVISÃO DE LITERATURA......................................................................18

3.1MALTODEXTRINA.......................................................................................................18

3.2DIGESTIBILIDADE DOS NUTRIENTES ............................................................20

3.3DIGESTIBILIDADE DOS CARBOIDRATOS........................................................21

3.4 PROCESSAMENTO.................................................................................................23

3.5 METABOLISMO PÓS ABSORTIVO DA GLICOSE E INSULINA.....................23

4 MATERIAL E MÉTODOS ....................................................................................25

4.1LOCAL …….....................................................................................................................25

4.5 DELINEAMENTO EXPERIMENTAL .................................................................28

4.6 PROCEDIMENTOS LABORATORIAIS ................................................................29

4.7 ANÁLISE ESTATÍSTICA …........................................................................29

5 RESULTADO E DISCUSSÃO..................................................................................

5.1 CONSUMO ............................................................................................................

5.2 DIGESTIBILIDADE APARENTE TOTAL DA MATÉRIA SECA E

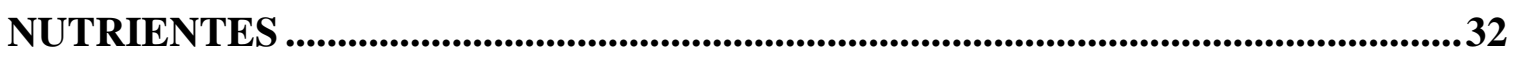

5.2 RESPOSTA GLICÊMICA E INSULINÊMICA...................................................42

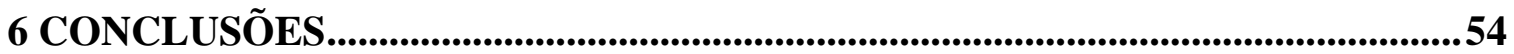

REFERÊNCIAS ....................................................................................................................55 


\section{INTRODUÇÃO}

O Homem a partir da domesticação do cavalo deu um passo muito importante em direção a um novo futuro. Isto é, montado ou sendo puxado por esses animais, ganhou velocidade, força e economizou tempo (PUOLI FILHO, 2004)

A indústria do cavalo é a maior no cenário agrícola, combinando negócios, esportes e recreação, dentro de um programa de impacto econômico envolvendo milhões de pessoas. Esta indústria envolve vários tipos de cavalos, associações e eventos. Basicamente dividida em 3 segmentos: corridas, competições e recreação (PARKER, 1998).

Os eqüinos têm grande importância no desenvolvimento do Brasil, o qual pode ser observada desde o Brasil - Colônia, quando o cavalo participou de todos os ciclos extrativistas, agrícolas e de mineração.

$\mathrm{Na}$ atualidade, este animal é usado para o trabalho rural e atividades de esporte e lazer (GUERRA; MEDEIROS, 2006).

Atualmente o Brasil possui o terceiro maior rebanho de eqüinos do mundo com 5,9 milhões de animais, sendo superado pela China com 7,9 milhões e pelo México com 6,3 milhões de cabeças. Cinco milhões de animais são utilizados para lida nas propriedades rurais, principalmente do gado bovino e os outros 900 mil cavalos, possuindo maior valor agregado, são representados por 23 associações de criadores de diferentes raças. O mercado de eqüinos movimenta cerca de R \$ 7,5 bilhões ao ano, gerando 3,2 milhões de empregos diretos e indiretos (GUERRA; MEDEIROS, 2006).

Embora muitas raças tenham sido selecionadas para satisfazer as várias exigências do homem, sabemos que, só é possível obter o máximo do potencial genético de cada indivíduo com a interação de vários fatores: nutrição correta, habilidade do cavaleiro e o mais importante, treinamento apropriado do animal (SNOW 1987).

$\mathrm{O}$ eqüino tem grande capacidade de realizar trabalhos, sua capacidade aeróbica e anaeróbica também são altas e relatadas duas vezes maiores que nos seres humanos (HODGSON e ROSE, 1994), uma vez que os cavalos apresentam maior peso médio e maior velocidade de corrida (BALDISSERA, 1997). 
Os cavalos de corrida de 400 metros podem atingir velocidades de $70 \mathrm{~km} / \mathrm{h}$, os cães podem até $60 \mathrm{~km} / \mathrm{h}$ em corridas de até 500 metros, e humanos aproximadamente $36 \mathrm{~km} / \mathrm{h}$ sendo que em corridas de $100 \mathrm{~km}$ atinge cerca de $16 \mathrm{~km} / \mathrm{h}$ e $1000 \mathrm{~km}$ atinge velocidades de 6 a 8 $\mathrm{km} / \mathrm{h}$. Os camelos em distancias de 4 a $10 \mathrm{~km}$ podem atingir até $36 \mathrm{~km} / \mathrm{h}$, ou seja as velocidades máximas nessas espécies variam sendo $19 \mathrm{~m} / \mathrm{s}$ em cavalos, $16,6 \mathrm{~m} / \mathrm{s}$ em cães e 10 a $11 \mathrm{~m} / \mathrm{s} \mathrm{em}$ humanos e camelos atletas (Figura 1) (HODGSON; ROSE, 1994).

A energia é necessária para bombear íons e moléculas orgânicas e manter gradientes iônicos necessários para gerar potenciais de ação e condutividade elétrica no sistema nervoso (HODGSON e ROSE, 1994).

No trato gastrointestinal, nutrientes como a glicose, são absorvidos pelo organismo. A glicose é transportada pelo sistema circulatório até o fígado, sendo convertida em glicogênio. No fígado é armazenada ou vai para o músculo sendo metabolizada em energia ou armazenada como glicogênio para ser usado futuramente. No músculo, o glicogênio é metabolizado a piruvato pela via glicolítica. Na via aeróbica o piruvato é metabolizado no ciclo do ácido tricarboxílico, formando posteriormente dióxido de carbono e água. Por via anaeróbica o piruvato é convertido a ácido lático. O ácido lático, o dióxido de carbono e a água são removidos do músculo através da corrente sanguínea. O dióxido de carbono é expelido através dos pulmões, a água através dos rins e o ácido lático é resintetizado a glicose no fígado (GUIMARÃES e ADELL, 1995).

O metabolismo no músculo esquelético é especializado em produzir adenosina trifosfato (ATP) como fonte imediata de energia (Lehninger et al., 2000). Para que ocorra a contração, os músculos precisam de energia. No início, essa energia é fornecida pela metabolização de combustíveis estocados no interior das células musculares. Quando cessados estes estoques de energia, o combustível passa a ser fornecido por outras áreas do corpo, como o fígado, onde são trazidos às miofibrilas pela corrente sanguínea sob a forma de glicose e de ácidos graxos livres (SILVA, 2005).

Dependendo do grau de atividade muscular os músculos irão utilizar ácidos graxos, corpos cetônicos e glicose como combustível, sendo que em repouso os combustíveis utilizados são ácidos graxos do tecido adiposo e corpos cetônicos do fígado, estes são oxidados e degradados a acetilcoenzima A, que entra no ciclo de Krebs para oxidação até dióxido de carbono (CO2), fornecendo ATP pela fosforilação oxidativa (Lehninger et al., 2000).

O glicogênio é metabolizado a glicose-1-fosfato (G-1-P) por fosforilase, esta é convertida a glicose-6-fosfato (G-6-P), que em seguida entra na via glicolítica anaeróbica. As reservas de 
glicogênio em cavalos chegam a $700 \mathrm{mmol}$ de glicose por $\mathrm{kg}$ de músculo, sendo para eles a maior fonte de combustível (HODGSON e ROSE, 1994).

A glicose sofre fosforilação a G-6-P no citosol da célula por hexoquinase, nessa reação requer a utilização de uma molécula de ATP, a G-6-P é convertido a frutose-6-fosfato (F-6-P) que é convertido a frutose-1,6-difosfato (F-1,6-P2) com a utilização de outra molécula de ATP. A F-1,6-P2 é metabolizada a duas moléculas de piruvato com a produção de 4 moléculas de ATP e 2 de NADH2, de maneira que o percurso glicolítico anaeróbico rende 3 moléculas de ATP para 1 molécula de glicogênio ou 2 moléculas de ATP para 1 molécula de glicose. No estágio final do percurso anaeróbico ocorre a conversão de piruvato a lactato em uma reação catalisada por lactato desidrogenase que também reoxida o NADH2. Pode ocorrer ainda do piruvato entrar na mitocôndria e participar do ciclo do TCA (HODGSON e ROSE, 1994).

A produção aeróbica de ATP ocorre dentro da mitocôndria (HODGSON e ROSE, 1994; BALDISSERA, 1997), envolvendo duas vias metabólicas, o Ciclo de Krebs e a cadeia de transporte de elétrons (BALDISSERA 1997), a partir da oxidação de gorduras e da glicose, resultando desta produção, dióxido de carbono e água, com a produção de 38 moléculas de ATP ao final da reação (BALDISSERA, 1997; LEHNINGER et al., 2000).

As coenzimas nicotinamida-adenina-dinucleotídeo (NAD) e flavina-adeninadinucleotídeo (FAD) atuam como carreadoras de hidrogênio e são reduzidas a NADH2 e FADH2. As coenzimas são essenciais para a fosforilação aeróbica, mas as suas concentrações dentro do músculo são baixas, devendo ser reoxidadas via transporte de cadeia de elétrons em que o oxigênio atua como aceitador final de hidrogênio para formar água (HODGSON; ROSE, 1994).

A glicose é fosforilada e degradada pela glicólise até piruvato, que é convertido em acetil - CoA e oxidado através do Ciclo de Krebs (Lehninger et al., 2000). O piruvato é derivado para o metabolismo anaeróbico de glicose e glicogênio no citoplasma, sendo transportado para dentro da mitocôndria pela atividade da piruvato desidrogenase, que converte piruvato em acetil coenzima A (acetil- CoA) por via aeróbica. A acetil- CoA entra no ciclo do ácido tricarboxílico (TCA) por combinação com o oxaloacetato (OAA). Neste ciclo existem várias desidrogenações e descarboxilações que consomem o grupo acetil do acetil- CoA, permitindo a recuperação do volume inicial de OAA. Além disso, são produzidos no ciclo 2 moléculas de $\mathrm{CO} 2$, transferidos 8 átomos de hidrogênio para formar 3 moléculas de NADH2 e 1 FADH2 e 1 molécula de ATP. A NADH2 e FADH2 são submetidas a fosforilação oxidativa. Cada molécula de NADH2 combina com $\mathrm{O} 2$ para formar $\mathrm{H} 2 \mathrm{O}$ em uma reação ligada a um percurso que combina 3 moléculas de ADP e 3 moléculas de Pi para formar 3 moléculas de ATP. Com o FADH2 ocorre 
uma reação similar produzindo 2 moléculas de ATP. O resultado final do ciclo do ácido tricarboxílico é a produção de 12 moléculas de ATP para cada molécula de acetil - CoA (HODGSON e ROSE, 1994).

Os cavalos possuem uma capacidade limitada de produzir energia por via aeróbica devido à disponibilidade do oxigênio no trabalho muscular (Evans, 2000). Com a continuidade do exercício, as células passam a utilizar mais a glicose (exercício moderado) e, devido a deficiência no aporte de oxigênio às células (exercício intenso), ocorre um desvio metabólico, onde se inicia a formação de ATP pelos processos glicolíticos (anaeróbicos) com formação de ácido lático (SILVA, 2005).

Morgado e Galzerano (2006) descrevem trecho citado por Lehninger et al. (1995) concluindo que a produção excessiva de lactato e seu acúmulo levam a queda do $\mathrm{pH}$, devido o aumento das concentrações de íons $\mathrm{H}+$, que é gerado pela dissociação do ácido lático em lactato e $\mathrm{H}+$ (SALES et al., 2005).

Com a intensa produção de lactato ocorre diminuição do $\mathrm{pH}$, podendo limitar a capacidade do trabalho por interferir na atividade enzimática muscular (THOMASSIAN, 2005). 


\section{OBJETIVO}

Esse estudo objetivou avaliar o uso da maltodextrina, como fonte alternativa de carboidrato solúvel, e verificar suas implicações sobre a digestibilidade aparente total e as respostas glicêmicas e insulinêmicas, bem como estar o potencial da maltodextrina como suplemento energético para cavalos atletas. 


\section{REVISÃO DE LITERATURA}

\subsection{Maltodextrina}

Quando se discute sobre a realização de exercícios de longa duração, sabe-se que um dos substratos degradado e utilizado é o carboidrato, o qual é armazenado na forma de glicose. A glicose, por sua vez, exerce um papel importante, pelo fato de servir como combustível primário (glicogênio) para a performance do músculo, principalmente durante exercícios intensos. Dessa forma recomenda-se a ingestão de carboidratos para atletas que realizam competições com duração igual ou superior a 1 hora, devido à sua rápida metabolização e por serem digeridos e absorvidos mais rapidamente que as proteínas ou lipídios (MAMUS et al., 2006).

Nieman et al. (2003), descrevem outros benefícios da suplementação com CHO, como, aumento das respostas imunes do organismo, principalmente no que diz respeito às inflamações. Uma dieta rica em carboidratos estimula a síntese da glutamina plasmática pós exercício (ZANKER et al., 1997).

Wolmore e Costill (2001), afirmam que durante a realização de um exercício de curta duração, mas, de intensidade máxima, o ATP é gerado a partir do CHO. Na realização de um exercício prolongado, a musculatura esquelética necessita de glicose para realizar a sua contração e produzir o movimento (MCARDLE, KATCH KATCH, 2001).

A maltodextrina é um derivado do amido com uma ampla gama de aplicações. O amido de milho tem sido amplamente utilizado como matéria prima na produção da maltodextrina (MOORE et al., 2005).

A maltodextrina pode ser classificada como um carboidrato de alto índice glicêmico e ao mesmo tempo complexo faz com que a glicose passe para a circulação sanguínea de forma mais lenta. Sendo assim a elevação da curva glicêmica se mantém por mais tempo (SAPATA et al., 2006). Aparentemente a maltodextrina causa um esvaziamento gástrico mais rápido, além de 
não possuir um paladar adocicado como a glicose, não causando desconfortos gástricos para a maioria das pessoas (COOGAN;SWANSON, 1992).

A modificação enzimática do amido pode produzir a maltodextrina (MOORE et al., 2005). Que é produzida por $\alpha$-amilase com ou sem ácido clorídrico, com diferentes pesos moleculares, de acordo com o método de produção e de fonte (MOORE et al., 2005).

A maltodextrina $\left(\mathrm{C}_{6} \mathrm{H}_{10} \mathrm{O}_{5}\right)$ n. $\mathrm{H}_{2} \mathrm{O}$ é um polímero de sacarídeos nutritivo, e não doce que consiste principalmente de unidades de glicose ligadas por um $\alpha-1,4$ limite de glicose, com dextrose equivalente (DE) inferior a 20 valores. Várias propriedades físicas e funcionais, tais como a doçura, compressão e viscosidade variam de acordo com o grau de hidrólise do amido, que é caracterizada pela determinação da dextrose equivalente (MOORE et al., 2005).

Coyle et al. (1986) e Coogan e Coyle (1987), afirmam que a refeição à base de polímeros de glicose, como a maltodextrina, administrada durante exercícios prolongados, produz energia necessária para protelar a fadiga, pelo menos em exercícios realizados sob intensidades de até $75 \%$ do $\mathrm{VO}_{2}$ máx.

Mamus et al. (2006), afirmam que a suplementação de CHO (maltodextrina) produz um aumento nos estoques de glicogênio muscular, permitindo que a competição se prolongue ou que a performance seja melhorada, mediante o retardo do início da fadiga. Este atraso da fadiga deve-se, principalmente, à prevenção do declínio da concentração da glicose sanguínea, a qual facilita proporções elevadas da oxidação de $\mathrm{CHO}$ durante os estágios finais da competição.

Sapata et al. (2006), avaliaram a resposta glicêmica no desempenho de indivíduos saudáveis após a ingestão de carboidratos. No estudo foi administrado 01 (um) grama de maltodextrina por kilograma $(\mathrm{kg})$ de massa corporal, e concluíram que após o consumo de bebida à base de maltodextrina os níveis glicêmicos apresentaram diferenças quando comparados à ingestão de glicose e da bebida placebo.

Um dos efeitos adicionais observados da ingestão de maltodextrina nas fases da competição, refere-se a elevação dos níveis de glicemia. Essa elevação é imprescindível para a performance física, pois altas concentrações de glicose favorecem a síntese de glicogênio muscular, e uma diminuição nessas concentrações pode levar à fadiga durante a competição (MAMUS et al., 2006).

Essa eficácia da ingestão de $\mathrm{CHO}$ para aumentar a síntese de glicogênio pode ser explicada de duas formas. Primeiramente, por uma maior disponibilidade do substrato, através do aumento da concentração de glicose sanguínea; e segundo, pelo aumento da concentração da 
insulina sistêmica, considerada como um potencial ativador da síntese de glicogênio (MAMUS et al., 2006).

Mamus et al. (2006) citam que outros estudos demonstraram que a ingestão à base de polímeros de glicose (maltodextrina) na competição, reduziram a taxa de fadiga nos últimos 30 minutos de competição, devido principalmente à manutenção dos níveis elevados de glicemia.

Mamus et al. (2006) declararam a importância de se manter níveis elevados de insulina durante a competição, pelo fato da insulina aumentar a captação da glicose sanguínea para o músculo e, principalmente no período pós competição, essa captação de glicose pelo músculo fica mais sensível à insulina, o que facilita a resistência dos estoques de glicogênio muscular. Verifica-se em algumas situações, quando o $\mathrm{CHO}$ (maltodextrina e glicose) é ingerido durante as fases da competição, as concentrações de insulina plasmática são tipicamente mantidas aos níveis de repouso ou, em alguns casos, aumentadas.

A ingestão de CHO (maltodextrina) antes e durante a competição aumenta os níveis de insulina, que podem ser mantidos durante todo o decorrer da competição (MAMUS et al., 2006).

As concentrações de cortisol aumentam significativamente durante a competição prolongada, demonstrando elevações dramáticas em estados de hipoglicemia. Com a ingestão de CHO (maltodextrina e glicose) o aumento de cortisol pode ser atenuado, quando comparado com a ingestão de placebo (MAMUS et al., 2006).

Ruffo (2004) em estudo com ratos, suplementados com maltodextrina 20 minutos antes da realização do exercício, dose individual calculada com base no peso dos animais, resultou em maior economia do glicogênio muscular para o músculo sóleo e maior economia do glicogênio hepático. Concluiu-se que as soluções carboidratadas utilizadas podem auxiliar no aumento da performance durante exercício físico, de caráter contínuo e prolongado, como ciclismo, corrida e natação.

\subsection{Digestibilidade dos nutrientes}

Frape (1992) citou que o tempo de permanência dos alimentos no estômago varia de 02 (duas) a 03 (três) horas e Konhke (1992) acrescentou um tempo mínimo de retenção de 20 minutos, limitando a ação de secreções gástricas. Essa velocidade de trânsito, associada ao pH 
baixo, restringe a ação da população microbiana na fermentação de açúcares e amido. O grau de digestão protéica no estômago é pequeno. A digestão, no intestino delgado dos equinos é intensa e, predominantemente enzimática. Os principais nutrientes digeridos são, proteína bruta (PB), extrato etéreo (EE), amido e açúcares, semelhante a digestão dos monogástricos (WOLTER 1975; HINTZ 1979; FRAPE 1992; KOHNKE 1992).

Wolter (1975) citou que a parede do intestino delgado é muito musculosa, rígida e ricamente inervada, propiciando a geração de fortes ondas de contração, o que facilitaria a progressão do conteúdo intestinal associado a sua grande fluidez, resultante do sinergismo das secreções salivar, gástrica e em grande quantidade pancreática, biliar e entérica. O conteúdo intestinal flui pelo intestino delgado a uma velocidade de trinta centímetros por minuto, demorando em média oito horas para percorrê-lo, dependendo da quantidade de fibra ingerida.

\subsection{Digestibilidade dos carboidratos}

Com relação às fontes de carboidratos utilizados nos concentrados, os equinos, quando selvagens, não possuíam o hábito de ingerir grãos, ou mesmo outras fontes de amido. Com a domesticação e o uso dos animais em eventos esportivos, os carboidratos passaram a ser utilizados como a principal fonte para atender as exigências energéticas (RADICKE et al., 1992).

Segundo Gray (1992), a estrutura do amido (amilose + amilopectina) é clivada na cavidade duodenal pela enzima alfa-amilase secretada pelo pâncreas. Desse modo originam-se dissacarídeos, trissacarídeos e alfa-dextrinas, que posteriormente, sofrem hidrólise, pela ação complementar de três enzimas presentes na borda em escova da superfície intestinal. $O$ monossacarídeo gerado como produto final, a glicose, é então co-transportado para o interior dos enterócitos através do $\mathrm{Na}+$, por uma proteína transportadora específica (75-kDA) presente na superfície da borda em escova, numa taxa limitante de assimilação de amido. Devido a esta digestão sequencial luminal e membranosa, seguida pelo transporte de glicose, o amido é assimilado de maneira muito eficiente em animais não ruminantes. Apesar da digestibilidade total do amido ser alta, podendo variar de 87 a 100\%, os equinos possuem baixa atividade da enzima alfa-amilase pancreática, o que pode comprometer a digestibilidade pré cecal de dietas com altas quantidades ou fontes morfologicamente complexas deste nutriente (KIENZLE, 1994b; MEYER, 1995). 
Kienzle et al. (1997) avaliaram o efeito da morfologia do amido na digestão de cavalos fistulados no jejuno caudal e no ceco, alimentados com dietas contendo diferentes grãos e processamentos. Os autores relataram que existem barreiras para digestão do amido no trato gastrointestinal, como; estrutura das plantas, por exemplo, uma firme conexão entre os grânulos de amido em grãos de milho, tanto como; a própria estrutura dos grânulos de amido. $\mathrm{O}$ amido da aveia, mais digerível, foi degradado pela exocorrosão ao redor dos grãos, ao contrário dos outros, menos digeríveis, o tipo de degradação do amido ocorreu pela endocorrosão via "PIN HOLES". O número e tamanho dos "PIN HOLES" aumentaram com a elevação da digestibilidade de amido pré-ileal. O efeito de várias formas de decomposição na digestibilidade pré-ileal aumentou com a destruição antecipada da estrutura original do amido. A expansão foi a forma mais efetiva, os grânulos foram destruídos completamente e o amido tornou-se solúvel.

Com objetivos semelhantes, Kienzle (1994), verificou que a digestibilidade do amido tende a decrescer com o aumento do consumo por refeição e que o processo de moagem mecânica tanto como a laminação ou trituração não alteram significativamente a digestibilidade de amido no intestino delgado, enquanto a trituração fina de grãos aumenta a digestibilidade. Da mesma forma, observou que a micronização e especialmente a expansão incrementam significativamente a digestibilidade do amido no intestino delgado de cavalos, atribuindo esses efeitos a maior ou menor destruição da estrutura botânica do amido durante o processamento.

A digestão do amido pode ser influenciada por fatores intrínsecos, como a forma física do alimento, a granulação, recristalização, complexos amilose lipídica, inibidores nativos da alfa amilase e, por fatores extrínsecos: mastigação, tempo de trânsito, concentração de alfa amilase no intestino, quantidade de amido ingerida e a presença de outros constituintes alimentares que podem retardar a hidrólise enzimática (ENGLYST et al., 1992 apud AMAN et al., 1995, p. ). Os autores ressaltam também a existência de uma porção indigerível, resistente à ação da alfaamilase, a qual escapa a digestão pré cecal.

Massey et al. (1985) avaliaram a digestão aparente parcial e pré cecal e pós ileal do amido, em um concentrado comercial fornecido em duas, três ou quatro refeições em intervalos, respectivamente, de doze, oito e seis horas entre as refeições. Os autores não observaram diferenças nos coeficientes de digestibilidade aparente parcial pré cecal e pós ileal do amido, concluindo que dietas com alta proporção da relação concentrado/volumoso (70/30\%) podem ser fornecidas em apenas duas refeições por dia para atender as exigências de energia digestível para mantença.

Segundo esses autores o amido digerido no intestino delgado apresentou aporte energético $42 \%$ superior ao do amido fermentado no rúmen. Teoricamente, é desejável que o 
amido escape da fermentação ruminal, evitando-se as perdas pela fermentação (ORSKOV, 1986).

\subsection{Processamento}

O processamento físico dos grãos consiste na quebra, moagem, trituração ou laminação de grãos secos, porém, as modificações físico-químicas envolvem a aplicação de calor, água e pressão (floculação, laminação a vapor e extrusão), os quais hidratam e incham (gelatinizam) as estruturas amorfas e cristalinas dos grãos de amido, aumentando a digestibilidade amilolítica das enzimas pancreáticas (MENEZES JR., 1999).

O nível de floculação e gelatinização do amido são determinados pelo tempo de exposição ao vapor, temperatura, umidade do grão, tamanho e distância entre os rolos e tipo de grão (OWENS et al. 1997; MENEZES JR., 1999). Esses fatores, tanto como o grau de trituração ou moagem do grão, podem afetar na digestibilidade do amido no trato gastrointestinal dos animais.

Segundo Gray (1992), a digestão e absorção de amido em cavalos aumentam significativamente pelo processamento de grãos, com aquecimento a $100^{\circ} \mathrm{C}$, por vários minutos antes de sua ingestão.

Por outro lado, Potter et al. (1992), afirmam que o processamento, aparentemente, tem um pequeno efeito sobre a digestibilidade em todo trato, mas, pode afetar o local de digestão de determinados nutrientes, por exemplo a digestibilidade do amido, do sorgo e milho no intestino delgado, aumenta com micronização e trituração, respectivamente.

\subsection{Metabolismo pós absortivo da glicose e insulina}

A concentração plasmática de glicose após a ingestão de alimento, chamada de resposta glicêmica, pode ser influenciada pelo tamanho da partícula, grau de processamento térmico, composição em proteína, gordura e fibra do alimento, estrutura bioquímica e processo de 
absorção do carboidrato, conteúdo e intervalo de tempo da refeição anterior (GUEZENNEC et al., 1995).

Potter et al. (1992) demonstraram que a moagem dos grãos pode melhorar a digestibilidade do amido no intestino delgado, porém, alimentos peletizados podem produzir um significativo aumento na glicose e insulina plasmáticas, quando comparada com a de alimentos menos processados.

Na maioria das vezes, todo carboidrato solúvel ingerido é absorvido para a corrente sangüínea e a concentração plasmática de outros monossacarídeos quando comparada com a de glicose é insignificante (STULL; RODIEK, 1988).

Rankin (1997) sugere que para completar a avaliação do índice glicêmico de um alimento, ou seja, a magnitude da resposta em glicose plasmática após sua ingestão, a concentração plasmática de insulina pode ser um bom indicativo da presença de açúcar na corrente sangüínea.

Segundo Davison et al (1991), a ingestão de grandes quantidades de carboidratos solúveis tem sido citada como responsável por alterações nas concentrações plasmáticas de alguns hormônios da tireóide. A ingestão de carboidratos altera o metabolismo dos hormônios da tireóide através da conversão mediada pela insulina, de tiroxina (T4) e em triiodotironina (T3). Os hormônios da tireóide tem sido citados como responsáveis pela regulação do crescimento esquelético e maturação das placas cartilaginosas.

De acordo com Arai et al. (1994), a glicose é a maior fonte de energia para animais e a glicólise é a melhor reação enzimática para a produção de ATP nas células.

Silva et al. (2008) concluíram que a maltodextrina, combinada ou não com acidificantes nas rações, resultou em maior vantagem econômica em comparação à lactose. Nesse estudo, a maltodextrina pode ser considerada alternativa às fontes de lactose para leitões desmamados. 


\section{MATERIAL E MÉTODOS}

\subsection{Local}

O experimento foi conduzido nas dependências do Setor de Equideocultura do Campus Administrativo de Pirassununga e no Laboratório de Bromatologia do Departamento de Nutrição e Produção Animal da Faculdade de Medicina Veterinária e Zootecnia da Universidade de São Paulo (FMVZ-USP).

\subsection{Animais}

Foram utilizados quatro equinos fêmeas, com idade aproximada de trinta meses, com peso médio de $400 \mathrm{Kg}$, pertencentes ao rebanho da USP. Os animais foram imunizados contra tétano, vermifugados e pulverizados contra ectoparasitas.

\subsection{Dietas e procedimento experimental}

Para a determinação das respostas glicêmicas e insulinêmicas foram utilizadas quatro dietas isoenergéticas e isoproteicas, cuja variação foi a substituição do amido extraído do milho pela maltodextrina (Tabela 1).

- Dieta 1: concentrado + amido (controle).

- Dieta 2: concentrado com 33,3\% de maltodextrina.

- Dieta 3; concentrado com $66,6 \%$ de maltodextrina.

- Dieta 4: concentrado com $100 \%$ de maltodextrina.

Tabela 1- Composição dos ingredientes e bromatologica dos concentrados experimentais 


\begin{tabular}{|c|c|c|c|c|}
\hline \multirow{3}{*}{ Ingredientes } & \multicolumn{4}{|c|}{ Concentrados experimentais $^{1}$} \\
\hline & \multirow{2}{*}{ Controle } & \multicolumn{3}{|c|}{ Maltodextrina } \\
\hline & & 33 & 66 & 100 \\
\hline Farelo de soja & 25,00 & 25,00 & 25,00 & 25,00 \\
\hline Casca de soja & 20,00 & 20,00 & 20,00 & 20,00 \\
\hline Amido & 50,00 & 33,00 & 17,00 & - \\
\hline Maltodextrina & - & 17,00 & 33,00 & 50,00 \\
\hline Núcleo mineral $^{2}$ & 4,00 & 4,00 & 4,00 & 4,00 \\
\hline Sal comum & 1,00 & 1,00 & 1,00 & 1,00 \\
\hline \multicolumn{5}{|l|}{ Nutrientes } \\
\hline Matéria seca $^{4}$ & 89,80 & 89,55 & 91,44 & 92,17 \\
\hline Matéria orgânica $^{5}$ & 91,88 & 91,53 & 91,98 & 92.29 \\
\hline Proteína bruta $^{5}$ & 16,22 & 13,64 & 15,62 & 13,28 \\
\hline Extrato etéreo $^{5}$ & 1,13 & 1,03 & 0,85 & 0,67 \\
\hline $\mathrm{CNF}^{3,4}$ & 56,38 & 60,35 & 57,84 & 60,95 \\
\hline $\mathrm{CHOT}^{3,5}$ & 74,53 & 76,86 & 75,51 & 78,34 \\
\hline Fibra Bruta ${ }^{5}$ & 11,01 & 10,81 & 11,35 & 11,16 \\
\hline $\mathrm{FDN}^{3,5}$ & 18,15 & 16,51 & 17,67 & 17,39 \\
\hline $\mathrm{FDA}^{3,5}$ & 10,78 & 11,25 & 11,00 & 12,19 \\
\hline Matéria mineral $^{5}$ & 8,12 & 8,47 & 8,02 & 7,71 \\
\hline Cálcio $^{5}$ & 1,11 & 1,21 & 1,21 & 1,10 \\
\hline Fósforo ${ }^{5}$ & 0,48 & 0,46 & 0,46 & 0,43 \\
\hline Energia Bruta $^{6}$ & 4,04 & 3,88 & 3,74 & 3,58 \\
\hline
\end{tabular}

${ }^{1} \mathrm{C}=$ Controle $0 \%$ substituição do amido pela maltodextrina no concentrado, $33=33 \%$ substituição do amido pela maltodextrina no concentrado, $66=66 \%$ substituição do amido pela maltodextrina no concentrado, $100=100 \%$ substituição do amido pela maltodextrina no concentrado. ${ }^{2}$ Composição por kg de mistura mineral: Ca180g; P 90g; mg 20g; S 20g; Na 100g; Zn 3.000mg; Cu 1.000mg; Mn 1.250mg; Fe 2.000mg ; Co 200mg; I 90mg; Se 36mg; F(máx.)900mg. ${ }^{3}$ Carboidratos não- fibrosos(CNF),carboidratos totais (CHOT), fibra em detergente neutro (FDN), fibra em detergente ácido (FDA). ${ }^{4}$ Porcentagem da matéria natural. ${ }^{5}$ Porcentagem da matéria seca. ${ }^{6} \mathrm{Mcal} / \mathrm{kg} \mathrm{MS}$

As dietas foram fornecidas duas vezes ao dia, com intervalos constantes as 7:00 horas e 19:00 horas, sendo a ração total (feno + concentrado) dividida em partes iguais entre os dois horários, adotando-se o consumo diário individual de 2,0\% do peso vivo em matéria seca, sendo $50 \%$ de concentrado e $50 \%$ de volumoso. O concentrado foi fornecido em um comedouro separado do volumoso e foi adotado um tempo de consumo para o concentrado de uma hora e meia a fim de padronizar e facilitar os estudos da taxa de passagem conforme metodologia adotada por Gobbs et al (1996). O volumoso foi oferecido simultaneamente ao concentrado, de acordo com Carvalho (1992). Água e suplemento mineral foram fornecidos ad libitum. As dietas continham 50\% de amido no concentrado, substituído em 33, 66\% e 100\% de maltodextrina. A formulação das dietas foi feita para atender as exigências de crescimento e mantença da categoria equina utilizada, segundo NRC (2007) (Tabela 2). 
Tabela 2- Composição dos ingredientes e bromatológica das dietas experimentais

\begin{tabular}{|c|c|c|c|c|}
\hline \multirow{3}{*}{ Ingredientes } & \multicolumn{4}{|c|}{ Dietas experimentais $^{1}$} \\
\hline & \multirow[t]{2}{*}{ Controle } & \multicolumn{3}{|c|}{ Maltodexrina } \\
\hline & & 33 & 66 & 100 \\
\hline Feno de Coast Cross & 50,00 & 50,00 & 50,00 & 50,00 \\
\hline Farelo de Soja & 12,50 & 12,50 & 12,50 & 12,50 \\
\hline Casca de Soja & 10,00 & 10,00 & 10,00 & 10,00 \\
\hline Amido & 25,00 & 16,50 & 8,50 & - \\
\hline Matodextrina & - & 8,50 & 16,50 & 25,00 \\
\hline Núcleo mineral $^{2}$ & 2,00 & 2,00 & 2,00 & 2,00 \\
\hline Sal Comum & 0,50 & 0,50 & 0,50 & 0,50 \\
\hline \multicolumn{5}{|l|}{ Nutrientes } \\
\hline Matéria seca $^{4}$ & 89,28 & 89,16 & 90,10 & 90,47 \\
\hline Matéria orgânica $^{5}$ & 92,34 & 92,16 & 92,39 & 92,54 \\
\hline Proteína bruta ${ }^{5}$ & 13,40 & 12,11 & 13,10 & 11,93 \\
\hline Extrato etéreo $^{5}$ & 1,88 & 1,83 & 1,74 & 1,65 \\
\hline $\mathrm{CNF}^{3,5}$ & 29,47 & 31,45 & 30,20 & 31,75 \\
\hline $\mathrm{CHOT}^{3,5}$ & 77,06 & 78,23 & 77,55 & 78,97 \\
\hline Fibra Bruta $^{5}$ & 23,56 & 23,46 & 23,73 & 23,64 \\
\hline $\mathrm{FDN}^{3,5}$ & 47,60 & 46,78 & 47,36 & 47,22 \\
\hline $\mathrm{FDA}^{3,5}$ & 24,33 & 24,57 & 24,44 & 25,04 \\
\hline Matéria mineral $^{5}$ & 7,67 & 7,84 & 7,62 & 7,46 \\
\hline Cálcio $^{5}$ & 0,80 & 0,85 & 0,85 & 0,79 \\
\hline Fósforo ${ }^{5}$ & 0,32 & 0,31 & 0,31 & 0,29 \\
\hline Energia Bruta ${ }^{6}$ & 4,15 & 4,07 & 4,00 & 3,92 \\
\hline
\end{tabular}

${ }^{1} \mathrm{C}=$ Controle $0 \%$ substituição do amido pela maltodextrina no concentrado, $33=33 \%$ substituição do amido pela maltodextrina no concentrado, $66=66 \%$ substituição do amido pela maltodextrina no concentrado, $100=100 \%$ substituição do amido pela maltodextrina no concentrado ${ }^{2}$ Composição por $\mathrm{kg}$ de mistura mineral: Ca180g; P 90g; mg 20g; S 20g; Na 100g; Zn 3.000mg; Cu 1.000mg; Mn 1.250mg; Fe 2.000mg ; Co 200mg; I 90mg; Se 36mg; F(máx.)900mg. ${ }^{3}$ Carboidratos não- fibrosos(CNF),carboidratos totais (CHOT), fibra em detergente neutro (FDN), fibra em detergente ácido (FDA). ${ }^{4}$ Porcentagem da matéria natural. ${ }^{5}$ Porcentagem da matéria seca. ${ }^{6} \mathrm{Mcal} / \mathrm{kg} \mathrm{MS}$

\subsection{Metodologia de coletas e processamento das amostras}

O experimento foi dividido em 4 (quatro) períodos de 11 dias cada, sendo os 8 (oito) primeiros dias de adaptação à dieta, 3 (três) dias para coleta total de fezes.

Amostras dos alimentos fornecidos e sobras foram retiradas diariamente durante os períodos de coletas, sendo acondicionados em sacos plásticos. As amostras de sobras foram compostas durante todo o período experimental, e foram acondicionadas em sacos plásticos para análise posterior. 
A colheita total de fezes foi feita em um período de 24 horas durante 03 (três) dias, com animais mantidos em baias, com piso de concreto, sem cama. As fezes foram acondicionadas em baldes plásticos, identificados por animal, e do total excretado, após homogeneização, foi retirado $10 \%$, acondicionado em sacos plásticos e congelados para posterior análise.

No primeiro dia de colheita de fezes foram realizadas as coletas de sangue em tubos previamente preparados com estabilizantes, a partir da veia jugular, 30 minutos antes, 30 minutos, 90 minutos, 150 minutos, 210 minutos após o fornecimento do concentrado para dosagem de glicose, do mesmo modo que Stull e Rodiek (1988) e para dosagem de insulina plasmática segundo o modelo proposto por Stull e Rodiek ( 1988). Também foi aferido o pH das fezes coletadas diretamente da ampola retal durante os mesmos momentos da coleta de sangue.

Ao final dos quatro períodos de coletas, as amostras de fezes totais dos alimentos fornecidos e das sobras foram descongeladas à temperatura ambiente, homogeneizadas manualmente, pesadas e secas em estufa de ventilação forçada a $65^{\circ} \mathrm{C}$, por 72 horas. Logo após foram moídas em moinhos com peneira de $1 \mathrm{~mm}$ quadrado. Amostras compostas das fezes foram feitas com base no peso seco, para cada animal e período. Todas as amostras após serem moídas, foram acondicionadas em recipiente de vidro, com tampa de polietileno e guardadas para posterior análise.

\subsection{Delineamento experimental}

Foi utilizado um delineamento experimental em Quadrado Latino 4x4 (quatro animais, quatro tratamentos) e medidas repetidas no tempo (Tabela 3).

Tabela 03 - Delineamento em quadrado latino para realizado

\begin{tabular}{lllll}
\hline Periodo Experimental & Controle & \multicolumn{3}{c}{ Matodextrina } \\
\cline { 3 - 5 } & & $33 \%$ & $66 \%$ & $100 \%$ \\
\cline { 3 - 5 } I & Amazonas & Avelã & Atenas & Avenca \\
II & Atenas & Avenca & Amazonas & Avelã \\
III & Avenca & Amazonas & Avelã & Atenas \\
IV & Avelã & Atenas & Avenca & Amazonas \\
\hline
\end{tabular}




\subsection{Procedimentos laboratoriais}

As análises de matéria seca (MS), matéria orgânica (MO), fibra em detergente neutro (FDN), fibra em detergente ácido (FDA), fibra bruta (FB), proteína bruta (PB), amido, matéria mineral (MM) e extrato etéreo (EE) foram realizados segundo a metodologia descrita por Silva (1990).

A análise do amido foi conduzida segundo o método enzimático descrito por Pereira e Rossi Junior (1998).

$\mathrm{Na}$ análise da glicose plasmática foi utilizada a técnica descrita por Bergmeyer (1975) e Tonkk (1972) e para insulina plasmática a rotina descrita por Yalow e Berson (1960).

\subsection{Análise estatística}

Os coeficientes de digestibilidade e os níveis plasmáticos de glicose e insulina foram analisados pelo programa computacional Statistical Analysis System (SAS, 2004), verificando-se anteriormente a normalidadedos resíduos pelo teste de Shapiro-Wilk (Proc Univariate) e a homogeneidade das variâncias pelo teste F.

Os coeficientes de digestibilidade aparente total foram analisados por regressão polinomial simples de acordo com os 4 níveis de substituição do amido pela maltodextrina pelo PROC REG do SAS e suas médias ajustadas foram comparadas através do teste de TUKEY $(\mathrm{P}<0,05)$ pelo PROC MIXED do SAS.

Os níveis plasmático de glicose e insulina foram analisados pela área abaixo da curva (AAC) que foi realizado através do PROC EXP do SAS e por regressão polinomial simples de acordo com os 4 níveis de substituição do amido pela maltodextrina pelo PROC REG do SAS e suas médias ajustadas foram comparadas através do teste de TUKEY $(\mathrm{P}<0,05)$ pelo PROC MIXED do SAS. 
A resposta glicêmica e insulinêmica em função do tempo foi realizada através de medidas repetida no tempo pelo PROC MIXED do SAS e por regressão polinomial simples de acordo com os 4 níveis de substituição do amido pela maltodextrina pelo PROC REG do SAS. 


\section{RESULTADO E DISCUSSÃO}

\subsection{Consumo}

Não foram observadas diferenças significativas $(P>0,05)$ em relação o consumo de matéria seca, matéria orgânica, proteína bruta, extrato etéreo, carboidratos não fibrosos, carboidratos totais, fibra bruta, fibra em detergente neutro, fibra em detergente ácido, matéria mineral, cálcio, fósforo e energia bruta (Tabela 4). As dietas foram formuladas para não haver qualquer diferença entre o consumo de nutrientes entre as dietas experimentais, pois sendo o consumo fixo e pré-determinado em função do peso vivo dos animais. Somente foi proposto um aumento no consumo da maltodextrina, onde foi observado um consumo máximo de maltodextrina de $2,5 \mathrm{~kg}$ /dia nas dietas com substituição de $100 \%$ do amido no concentrado por maltodextrina.

Tabela 04- Consumo da ração, feno, concentrado, maltodextrina e nutrientes em função das dietas experimentais.

\begin{tabular}{|c|c|c|c|c|}
\hline \multirow{3}{*}{ Consumo } & \multicolumn{4}{|c|}{ Dietas experimentais $^{1}$} \\
\hline & \multirow[t]{2}{*}{ Controle } & \multicolumn{2}{|c|}{ Maltodexrina } & \multirow[b]{2}{*}{100} \\
\hline & & 33 & 66 & \\
\hline \multicolumn{5}{|c|}{ (kg/dia) } \\
\hline Dieta Total & 10,00 & 10,00 & 10,00 & 10,00 \\
\hline Feno & 5,00 & 5,00 & 5,00 & 5,00 \\
\hline Concentrado & 5,00 & 5,00 & 5,00 & 5,00 \\
\hline Maltodextrina & - & 0,85 & 1,70 & 2,50 \\
\hline Tempo (min) & 52,00 & 59,00 & 62,00 & 73,00 \\
\hline Peso dos animais $(\mathrm{kg})$ & 441 & 442 & 459 & 461 \\
\hline \multicolumn{5}{|l|}{ Nutrientes } \\
\hline \multicolumn{5}{|c|}{ (kg/dia) } \\
\hline Matéria seca & 13,37 & 13,35 & 13,45 & 13,48 \\
\hline Matéria organic & 13,87 & 13,86 & 13,88 & 13,89 \\
\hline Proteína bruta & 1,87 & 1,74 & 1,84 & 1,72 \\
\hline Extrato etéreo & 0,32 & 0,31 & 0,31 & 0,30 \\
\hline Fibra Bruta & 4,16 & 4,15 & 4,18 & 4,17 \\
\hline $\mathrm{FDN}^{2}$ & 8,61 & 8,53 & 8,59 & 8,57 \\
\hline FDA $^{2}$ & 4,33 & 4,35 & 4,34 & 4,40 \\
\hline \multirow{2}{*}{\multicolumn{5}{|c|}{ mideria minteral }} \\
\hline & & & & \\
\hline Cálcio & 103,50 & 108,50 & 108,50 & 103,00 \\
\hline Fósforo & 39,00 & 38,00 & 38,00 & 36,50 \\
\hline \multicolumn{5}{|c|}{ (Mcal/dia) } \\
\hline Energia Bruta & 55,40 & 54,28 & 53,72 & 52,79 \\
\hline
\end{tabular}


Não foi observado efeito das dietas sobre a aceitabilidade dos animais no decorrer do período experimental, podendo ser observado um consumo de $100 \%$ das dietas em um tempo médio de 61 minutos.

\subsection{Digestibilidade aparente total da matéria seca e nutrientes}

Não foi observado efeito linear, quadrático ou desvio $(\mathrm{P}>0,05)$ para o $\mathrm{pH}$ das fezes e os coeficientes de digestilidade aparente total da matéria seca, matéria orgânica, proteína bruta, extrato etéreo, carboidratos não fibrosos, carboidratos totais, fibra bruta, fibra em detergente neutro, fibra em detergente ácido. Em relação ao coeficiente de digestibilidade aparente total do amido, não foi observado efeito ( $\mathrm{P}>0,05)$, apesar da proposta diminuição do nutriente nas rações experimentais (Tabela 5).

KIENZLE et al. (1997) avaliaram o efeito da morfologia do amido na digestão de cavalos fistulados no jejuno caudal e no ceco, alimentados com dietas contendo diferentes grãos e processamentos. Os autores relataram que existem barreiras para digestão do amido no trato gastrointestinal, como; estrutura das plantas, por exemplo, uma firme conexão entre os grânulos de amido em grãos de milho, tanto como; a própria estrutura dos grânulos de amido.

No entanto ao se submeterem as médias ajustadas dos coeficientes de digestibilidade aparente total ao teste de media, foram encontradas diferenças significativas $(\mathrm{P}<0,05)$ entre as dietas propostas no presente estudo (Tabela 5).

Quando se analisou o coeficiente de digestibilidade aparente total da matéria seca se observou um maior valor $(\mathrm{P}<0,05)$ para a ração com $100 \%$ de substituição do amido pela maltodextrina no concentrado, sendo encontrado um menor valor para a ração com $33 \%$ de substituição do amido pela maltodextrina no concentrado. Este resultado observado pode ser justificado pelas diferenças nutricionais entre o amido e a maltodextrina, onde se observa uma superioridade nutricional para a maltodextrina (Figura 1). 
- Matéria Seca $\square$ Matéria Orgânica

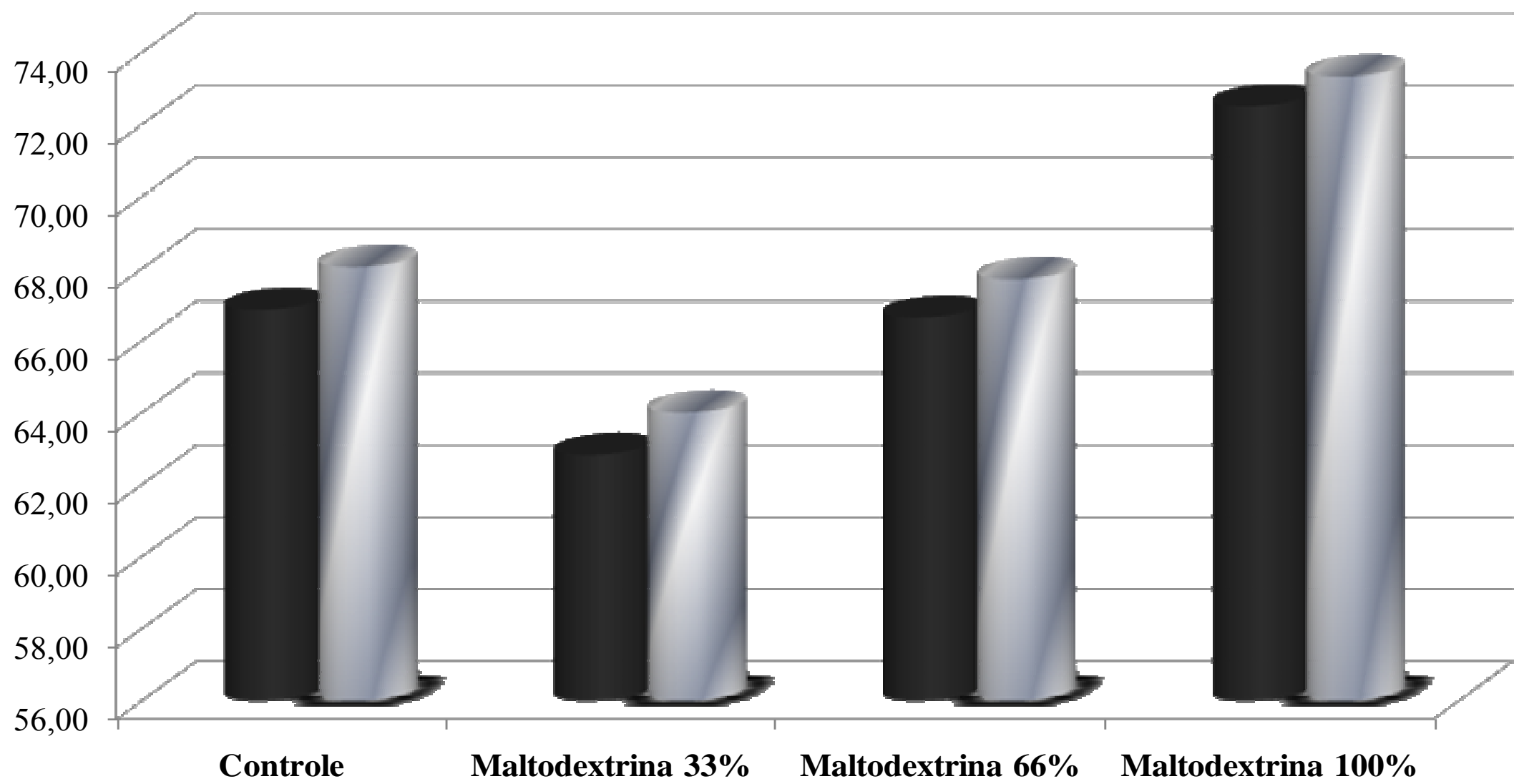

Figura 1 - Coeficientes de digestibilidade da matéria seca e da matéria orgânica em função das rações experimentais 
Os coeficientes de digestibilidade aparente da matéria seca do presente trabalho apresentaram valores $(\mathrm{P}<0,05)$ que variaram de 62,84 a $72,52 \%$ para os níveis crescentes de inclusão de maltodexrtina no concentrado. Estes valores podem ser considerados satisfatórios para estudos de digestibilidade em dietas para eqüinos. Experimentos com eqüinos machos, de diferentes idades e utilizando rações completas, com algumas variações nos ingredientes utilizados, relataram valores de digestibilidade aparente da matéria seca variando de 58,2 a 86,5\% (PEREIRA et al., 1989; MANZANO \& MANZANO, 1990; ARAÚJO, 1992; WHITAKEr \& CARVALHO, 1997; ALMEIDA et al., 1998; GONÇALVES et al., 1998; OLIVEIRa \& FURTADO, 2001;SANTOS et al., 2002).

Quadros et al.(2004) trabalharam em ensaio de digestibilidade com potros, onde os animais receberam dietas completas a base de feno de tifton e casca de soja, observaram valores de digestibilidade aparente total da matéria seca semelhante ao do presente estudo, havendo uma variação de 62,48 a $82,77 \%$ e uma média de $73,52 \%$. No presente estudo foi observado uma menor variação entre os tratamentos 62,84 a 72,55\% e uma média de $67,22 \%$.

Morgado et al.(2008) mensuraram a digestibilidade da matéria seca e dos nutrientes em eqüinos recebendo dietas a base de feno de coast cross na mesma proporção volumoso concentrado do presente estudo, e observaram valores inferiores ao deste estudo. De maneira semelhante os autores supracitados encontraram valores inferiores ao deste estudo para os coeficientes de digestibilidade da fibra em detergente neutro e fibra em detergente ácida.

De mesma forma foi observado uma superioridade $(\mathrm{P}<0,05)$ para a ração com $100 \%$ de substituição do amido pela maltodextrina no concentrado em relação aos coeficientes de digestibilidade aparente total da matéria orgânica, proteína bruta, fibra em detergente neutro e fibra em detergente ácido. Para todos os coeficientes de digestibilidade aparentes totais acima mencionados foram observados um menor valor para a ração com $33 \%$ de substituição do amido pela maltodextrina no concentrado (Figuras 2 e 3 ). 
Proteina buta

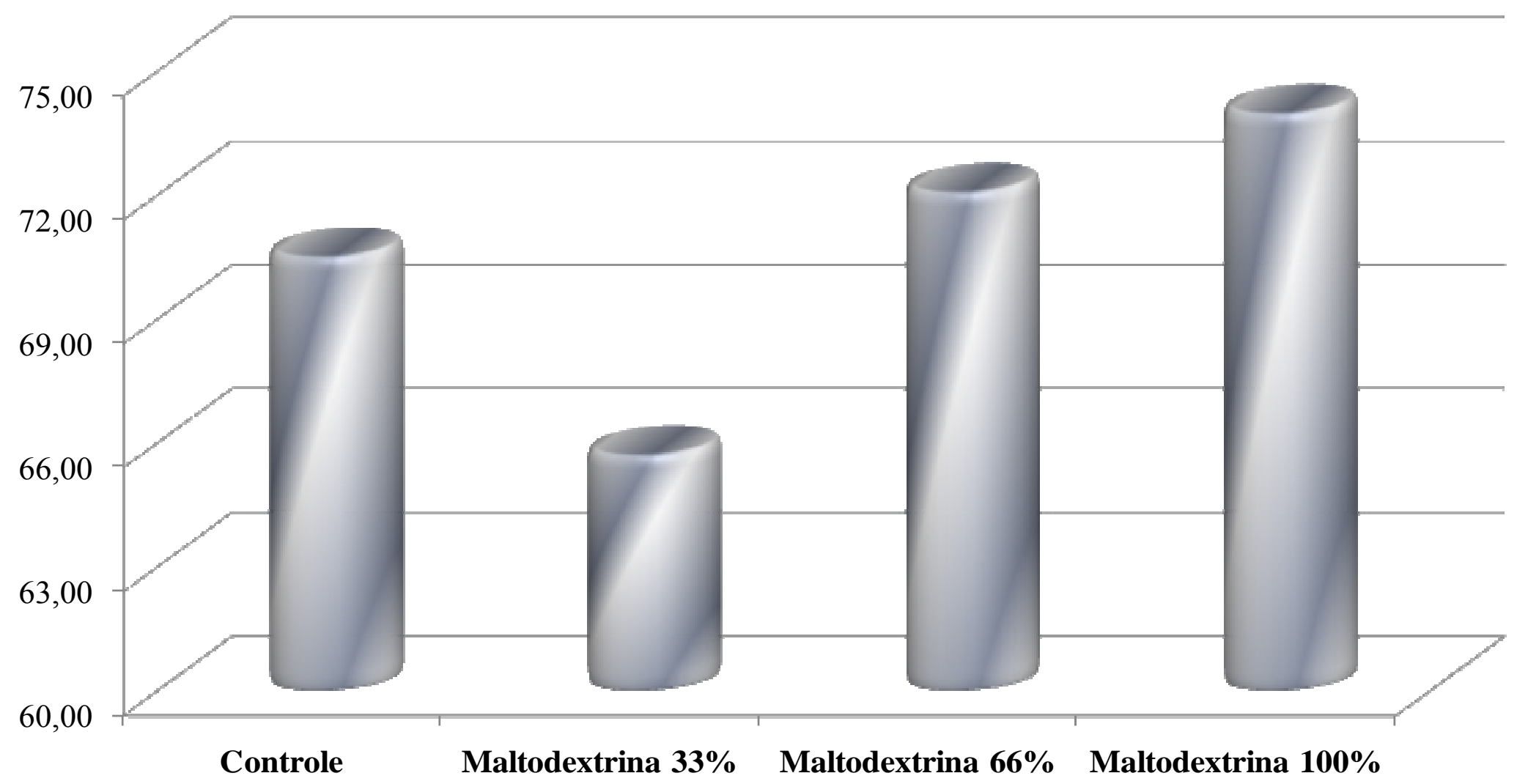

Figura 2 - Coeficientes de digestibilidade da proteína bruta em função das rações experimentais. 
Estes resultados observados refletem que a complexidade da fonte de carboidrato para dietas de eqüinos tem grande influencia na digestibilidade dos nutrientes, visto que os melhores resultados foram encontrados para a ração com maior teor de maltodextrina, que é uma fonte de carboidrato menos complexa que o próprio amido. Este resultado se confirma tendo em vista que a fonte do amido nas dietas foi milho moído.

Quadros et al.(2004) trabalharam em ensaio de digestibilidade com potros, onde os animais receberam dietas completas a base de feno de tifton e casca de soja, observaram valores de digestibilidade aparente total da fibra em detergente neutro e fibra em detergente ácido superiores ao do presente estudo,onde observaram médias de 68,60 e 65,97\% , respectivamente para fibra em detergente neutro e ácido, enquanto no presente estudo foi observado valores médio de 57,24 e $51,10 \%$, respectivamente.

Gobesso et al.(2008), suplementaram eqüinos com duas fontes de amidos diferentes, associadas a dois tipos de processamentos, as fontes de amido utilizadas foram o milho e o sorgo triturados ou extrusados. Neste estudo os autores encontraram melhores coeficientes de digestibilidade aparentes totais da matéria orgânica, proteína bruta, fibra em detergente neutro, fibra em detergente ácida, para o tratamento onde o amido possivelmente se encontrava em sua formam menos complexa. Estes resultados são semelhantes aos encontrados no presente estudo, onde foram observados melhores coeficientes de digestibilidade para as rações com maltodextrina. 
- Fibra em detergente neutro

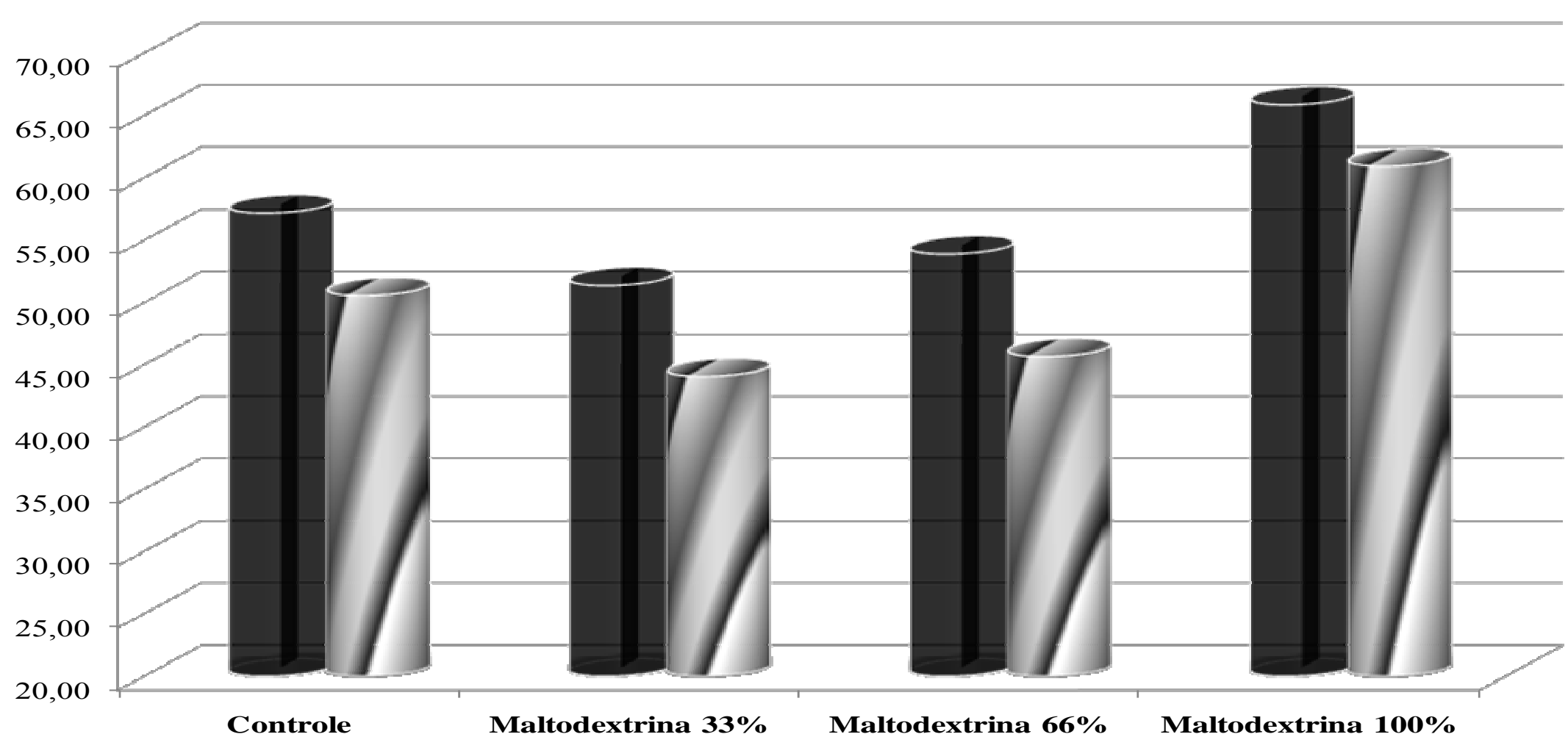

Figura 3 - Coeficientes de digestibilidade da fibra em detergente neutro e fibra em detergente ácido em função das rações experimentais. 
Weber \& Ehrlein (1998) verificaram maior absorção dos carboidratos e da gordura de dietas enterais contendo maltodextrina em comparação a dietas contendo glicose administradas a suínos, em razão da menor taxa de fluxo e da maior absorção de água, favorecidas pela menor osmolaridade das dietas com maltodextrina.

Silva et al. (2008), avaliando os efeitos da suplementação dietética de maltodextrina em substituição parcial à lactose sobre o desempenho, a digestibilidade em leitões desmamados, não verificaram influência da maltodextrina nos coeficientes de digestibilidade aparente de MS, PB e EB ( $\mathrm{P}>0,05)$, devido essa fonte de carboidrato poder ter contribuído para a indução da atividade das carboidrases intestinais, além de apresentar menor osmolaridade em comparação à lactose o que possibilitou aos leitões aproveitar de maneira semelhante as rações contendo ou não maltodextrina.

Não foi observada diferença significativa $(\mathrm{P}>0,05)$ entre as rações experimentais para os coeficientes de digestibilidade aparente totais do extrato etéreo, fibra bruta e para o $\mathrm{pH}$ das fezes. Estes resultados estão de acordo com a composição bromatológica das dietas, bem como o consumo desses nutrientes pelos animais (Figura 4).

Tabela 5- Medias, coeficientes de variação (CV) dos coeficientes de digestibilidade aparente total em função das rações experimentais

\begin{tabular}{|c|c|c|c|c|c|c|c|c|}
\hline \multirow[t]{3}{*}{ Variaveis $^{2}$} & \multicolumn{4}{|c|}{ Dietas experimentais $^{1}$} & \multirow[t]{3}{*}{ Media } & \multirow{2}{*}{$\begin{array}{l}\text { CV } \\
(\%)\end{array}$} & \multicolumn{2}{|c|}{ Valor de $\mathrm{P}$} \\
\hline & Controle & & altodextr & & & & Linear & Quad \\
\hline & & 33 & 66 & 100 & & & & \\
\hline $\mathrm{pH}$ das Fezes & 6,52 & 7,10 & 6,85 & 6,95 & 6,85 & 5,50 & 0,211 & 0,196 \\
\hline Matéria seca & $66,87^{\mathrm{ab}}$ & $62,84^{\mathrm{b}}$ & $66,66^{\mathrm{ab}}$ & $72,52^{\mathrm{a}}$ & 67,22 & 11,69 & 0,196 & 0,172 \\
\hline Matéria orgânica & $68,06^{\mathrm{ab}}$ & $64,01^{\mathrm{b}}$ & $67,72^{\mathrm{ab}}$ & $73,35^{\mathrm{a}}$ & 68,29 & 11,07 & 0,201 & 0,163 \\
\hline Proteína bruta & $70,52^{\mathrm{ab}}$ & $65,72^{b}$ & $72,08^{\mathrm{ab}}$ & $73,99^{\mathrm{a}}$ & 70,58 & 9,27 & 0,219 & 0,266 \\
\hline Extrato etéreo & 68,56 & 76,64 & 75,15 & 79, & 75,08 & 16,35 & 0,082 & 0,658 \\
\hline Fibra bruta & 53,11 & 47,99 & 51,01 & 59,51 & 52,91 & 22,53 & 0,253 & 0,133 \\
\hline FDN & $57,18^{\text {ab }}$ & $51,38^{\mathrm{b}}$ & $56,14^{\mathrm{ab}}$ & $64,25^{\mathrm{a}}$ & 57,24 & 19,67 & 0,194 & 0,130 \\
\hline FDA & $50,56^{\mathrm{a}}$ & $44,07^{\mathrm{b}}$ & $50,26^{\mathrm{ab}}$ & $59,51^{\mathrm{a}}$ & 51,10 & 27,06 & 0,164 & 0,142 \\
\hline Amido & 98,58 & 98,39 & 98,36 & 98,60 & 98,48 & 0,41 & 0,967 & 0,202 \\
\hline
\end{tabular}


Mesmo com a redução dos teores de amido como inclusão da maltodextrina, não se observou diferença significativa $(\mathrm{P}>0,05)$ para o coeficiente de digestibilidade aparente total do amido em relação às rações experimentais. Apesar da digestibilidade total do amido ser alta, podendo variar de 87 a $100 \%$, os eqüinos possuem baixa atividade da enzima alfa-amylase pancreática, o que pode comprometer a digestibilidade pré-cecal de dietas com altas quantidades ou fontes morfologicamente complexas deste nutriente (KIENZLE, 1994b e MEYER, 1995).

Essa semelhança foi observada também por Kienzle (1994) e, em experimento no qual a digestibilidade aparente total de amido de diversas dietas variou muito pouco, em virtude da alta digestão microbiana desse nutriente. Resultado semelhante foi observado por Gobesso et al.(2008), quando submeteu eqüinos a dietas com diferentes fonte de amido associadas a diferentes processamentos.

Os resultados observados neste experimento refletiram as condições de cada concentrado testado e, em alguns casos, observaram-se resultados semelhantes aos obtidos por Meyer et al. (1995), que concluíram que podem ocorrer variações individuais na digestibilidade de um mesmo alimento, causadas pelo comportamento durante a ingestão do alimento (tempo de mastigação), pela alteração de peristaltismo, por diferenças na produção de enzimas. 
Extrato etéreo $\square$ Fibra bruta

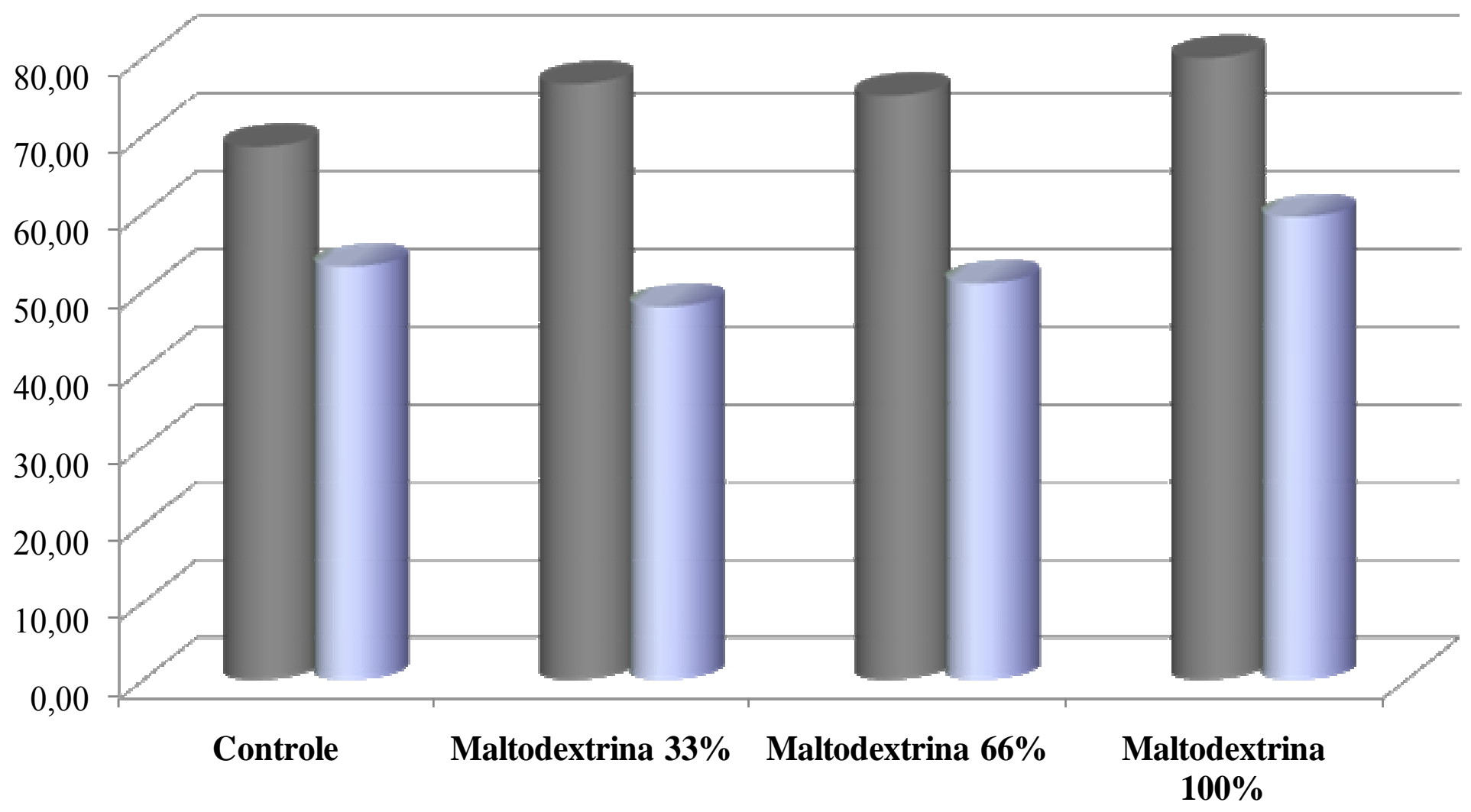

Figura 4 - Coeficientes de digestibilidade do extrato etéreo, fibra bruta e matéria mineral em função das rações experimentais. 


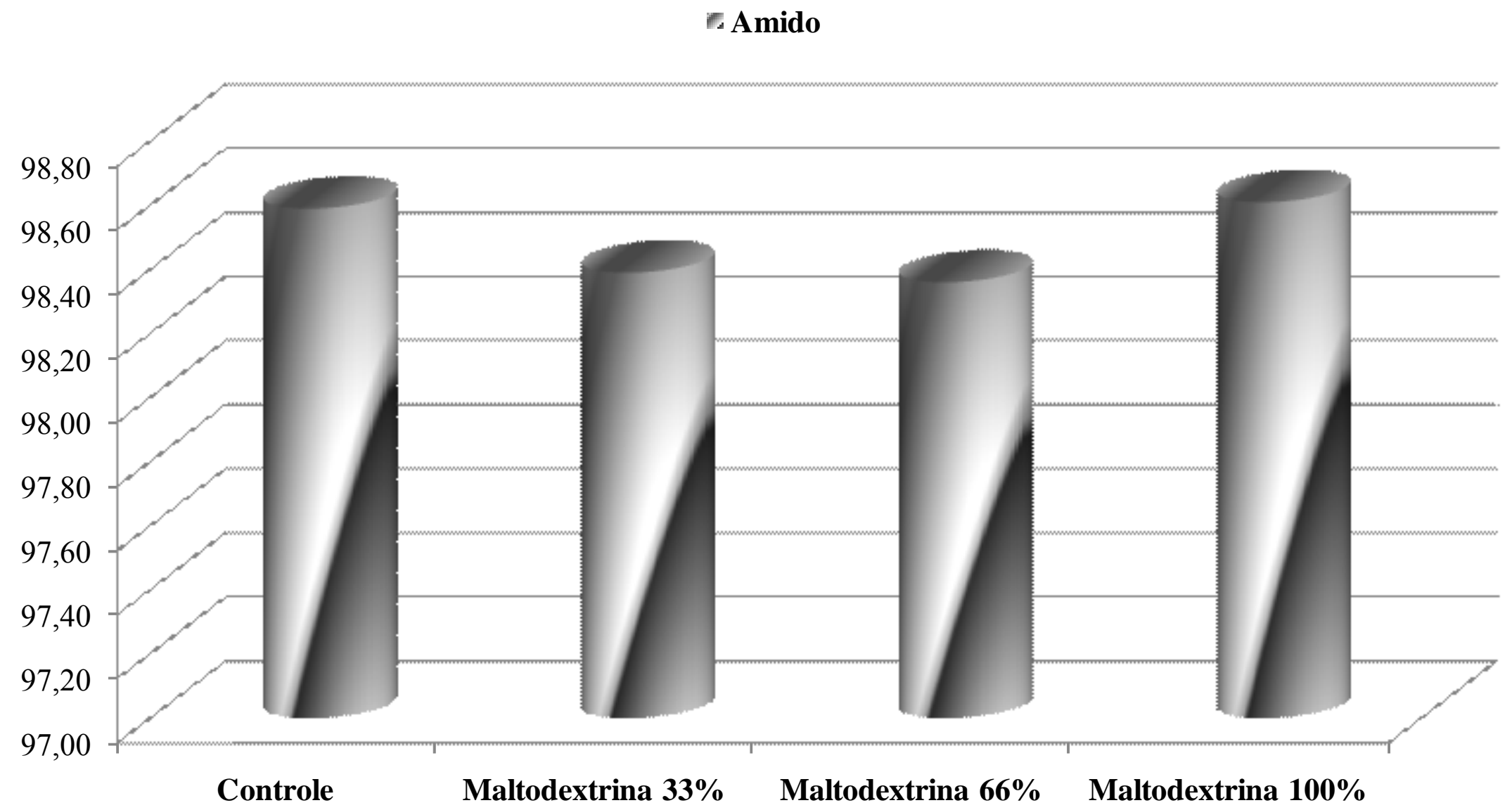

Figura $5-$ Coeficientes de digestibilidade do amido, em função das rações experimentais. 


\subsection{Resposta Glicêmica e Insulinêmica}

Para as análises da resposta glicêmica e insulinêmica foi calculada a área abaixo da curva (AAC) para as duas variáveis em questão (Tabela 6). Essa técnica permite uma melhor compreensão dos valores obtidos em ensaios de dosagem de parâmetros bioquímicos plasmáticos.

A concentração plasmática de glicose após a ingestão de alimento, chamada de resposta glicêmica, pode ser influenciada pelo tamanho da partícula, grau de processamento térmico, composição em proteína, gordura e fibra do alimento, estrutura bioquímica e processo de absorção do carboidrato, conteúdo e intervalo de tempo da refeição anterior (GUEZENNEC et al., 1995).

Em relação a área abaixo da curva (AAC), gerada pelos valores plasmáticos de glicose observados em 5 tempos distintos pós-alimentação, observou-se efeito quadrático $(\mathrm{P}<0,05)$. Pode-se observar uma um maior valor $(\mathrm{P}<0,05)$ para a ração com $100 \%$ de substituição do amido pela maltodextrina no concentrado.

Analisando os dados observados, fica explícito que o melhor nível de substituição do amido pela maltodextrina seria $66 \%$. Fazendo-se uma extrapolação dos dados e analisando a equação de $2^{\circ}$ grau gerada por esta variável, pode-se calcular o ponto ótimo da substituição do amido pela maltodextrina no concentrado. O valor estimado foi de $77 \%$ da substituição do amido pela maltodextrina no concentrado (Figura 6). A maltodextrina pode ser classificada como um carboidrato de alto índice glicêmico e ao mesmo tempo complexo faz com que a glicose passe para a circulação sanguínea de forma mais lenta. Sendo assim a elevação da curva glicêmica se mantém por mais tempo (SAPATA et al., 2006). 


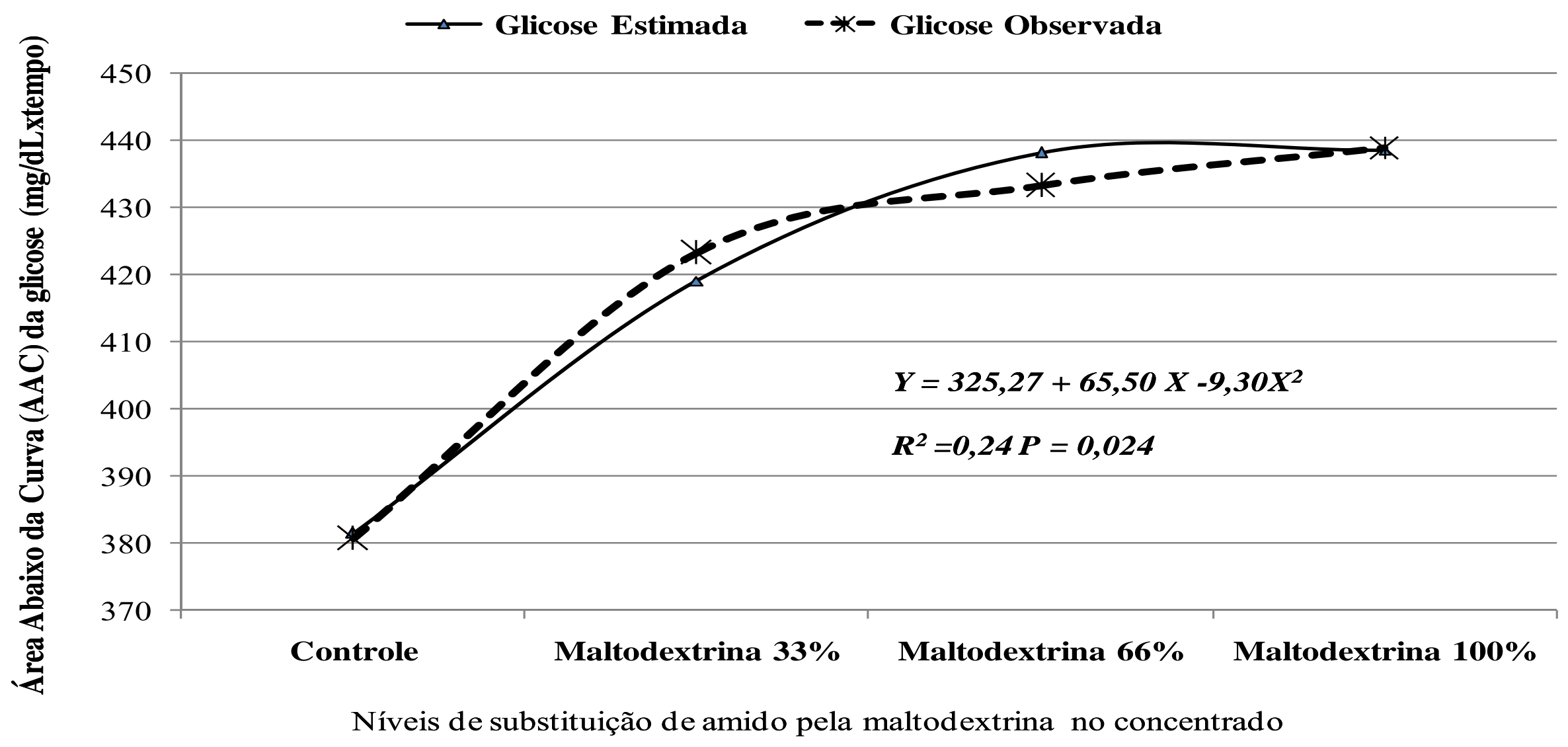

Figura 6 - Área abaixo da curva (AAC) dos níveis estimatimados e observados de glicose plasmática, em função das dietas experimentais 
Stull \& Rodiek et al.(1988) trabalharam com quatro potros quarto de milha e avaliaram 4 dietas com diferentes proporções de feno de coast cross e concentrado comercial, na dieta com $50 \%$ de feno e $50 \%$ de concentrado, os autores observaram uma área abaixo da curva para a glicose em média de 308,24 mg.hora/dL, resultado inferior a média deste estudo, fato este justificado pela adição de maltodextrina nas dietas experimentais.

Gordon et al.(2008) realizaram ensaio de resposta glicemia com 6 potros quarto de milha avaliando dietas com baixo nível de açúcar e altos níveis de amido, com 3 diferentes fontes de processamento do concentrado pellet $(4 \mathrm{~mm})$, extrusada $(5 \mathrm{~mm})$ e oval $(19 \mathrm{~mm})$, observaram uma área abaixo da curva para a glicose em média de 278,10 (mg/dL),h resultado inferior a média deste estudo, reforçando o fato de que a maltodextrina mantém níveis glicêmicos superiores a dietas com amido por um período de tempo superior.

Gobesso et al.(2008), suplementaram eqüinos com duas fontes de amidos diferentes, associadas a dois tipos de processamentos, as fontes de amido utilizadas foram o milho e o sorgo triturados ou extrusados. Neste estudo os autores encontraram em média uma área abaixo da curva para a glicose de $553,79 \mathrm{mg} / \mathrm{dL}$, proporcionalmente ao mesmo período de colheita ao do presente estudo, resultado este superior ao deste estudo.

Ao se analisar a área abaixo da curva (AAC) para a variável insulina se observou uma maior área $(\mathrm{P}<0,05)$ para a ração com $100 \%$ de substituição do amido pela maltodextrina no concentrado. Resultado este compatível com a maior área abaixo da curva da glicose.

Stull \& Rodiek et al.(1988) trabalharam com quatro potros quarto de milha e avaliaram 4 dietas com diferentes proporções de feno de coast cross e concentrado comercial, na dieta com $50 \%$ de feno e $50 \%$ de concentrado, os autores observaram uma área abaixo da curva para a insulina em média de $36,89 \mu \mathrm{UI} / \mathrm{mL}$, resultado semelhante a média deste estudo.

No entanto Gordon et al.(2008) observaram uma área abaixo da curva para a insulina de em média de $25,78 \mu \mathrm{UI} / \mathrm{mL}$ resultado inferior a média deste estudo.Mesmo resultado obtido por Gobesso et al.(2008), onde suplementaram eqüinos com duas fontes de amidos diferentes, associadas a dois tipos de processamentos, as fontes de amido utilizadas foram o milho e o sorgo triturados ou extrusados.

Observou-se ainda efeito linear $(\mathrm{P}<0,05)$ para a área abaixo da curva da insulina. E analisando a equação encontrada para esta variável observa-se uma resposta aditiva, onde para cada aumento de $1 \%$ da substituição do amido pela maltodextrina no concentrado se observou um aumento de 23,17 unidades na área abaixo da curva gerada pelos níveis plasmáticos de insulina obtidos após 5 tempos de colheita pós alimentação dos animais. A ingestão de 
maltodextrina aumenta os níveis de insulina que podem ser mantidos durante todo o decorrer da competição (MAMUS et al., 2006).

Tabela 6- Medias, coeficientes de variação (CV) da área abaixa da curva (AAC) em função das rações experimentais

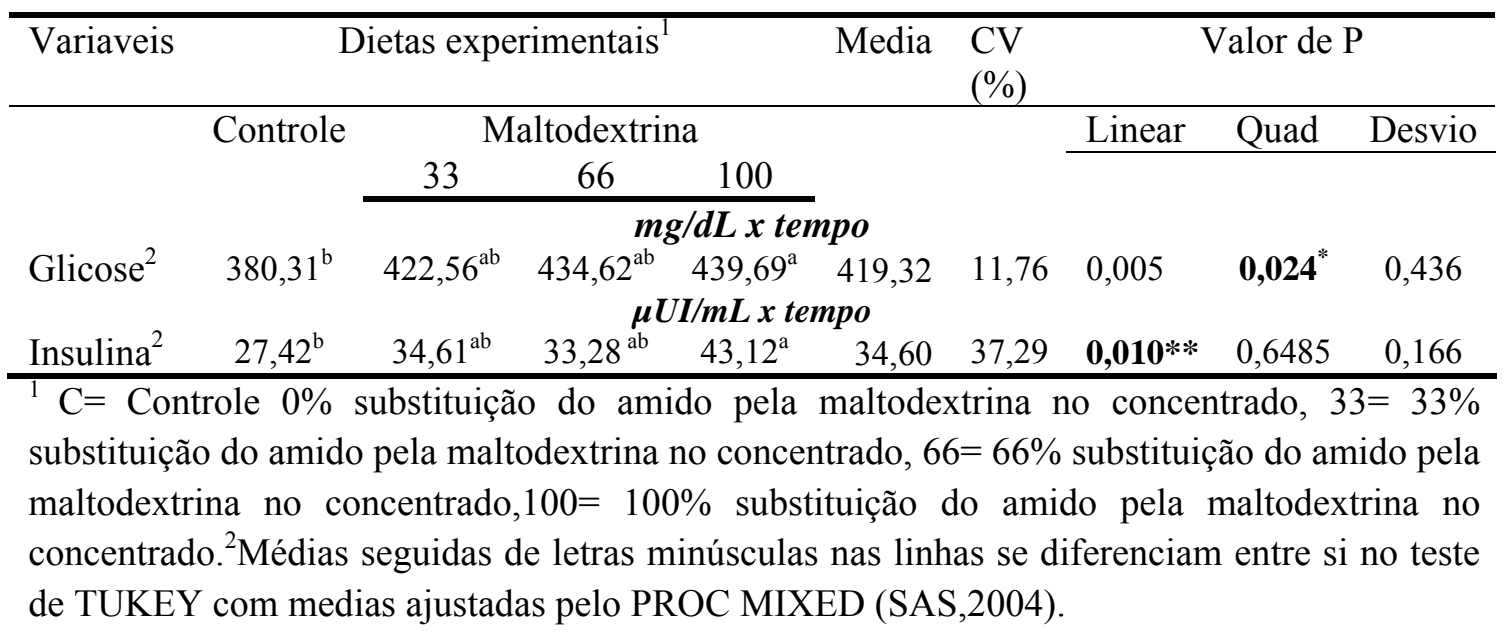

GLICOSE $^{*}=325,27+65,50 X-9,30 X^{2} R^{2}=0,24$, INSULINA $^{* *}=23,17+4,57 X R^{2}=0,17$.

Ao se analisar a resposta glicêmica e insulinêmica dos animais de acordo com as rações experimentais em função dos tempos de colheitas foram observados resultados que complementam os dados obtidos com a área abaixo da curva para as mesmas variáveis (Tabela 7).

Em relação níveis plasmáticos de glicose não foi observado efeito $(\mathrm{P}>0,05)$ de dieta $\mathrm{e}$ interação entre a dieta e os tempos de colheita, no entanto foi observado efeito $(\mathrm{P}<0,05)$ de tempo, onde se observou um aumento nos níveis plasmáticos de glicose independentemente da substituição do amido pela maltodextrina nos concentrados (Tabela 8).

Em relação à resposta glicêmica foi observado um comportamento linear $(\mathrm{P}<0,05) \mathrm{em}$ função da substituição do amido pela maltodextrina nos concentrados. Analisando a equação da reta pode se observar que para $1 \%$ de substituição do amido pela maltodextrina nos concentrados há um aumento de $95,80 \mathrm{mg} / \mathrm{dL}$ no nível plasmático de glicose. Este comportamento pode ser observado até o tempo de 90 minutos pós- alimentação (Figura 7).

Analisando o pico de plasmático de glicose em função das rações experimentais pode se observar que a ração com $66 \%$ de substituição do amido pela maltodextrina apresentou maior pico de glicose no tempo de 90 minutos pós-alimentação, também foi observado que as rações 
com substituição do amido pela maltodextrina apresentaram uma maior persistência nos níveis plasmáticos de glicose em relação a ração controle (Figura 7). 


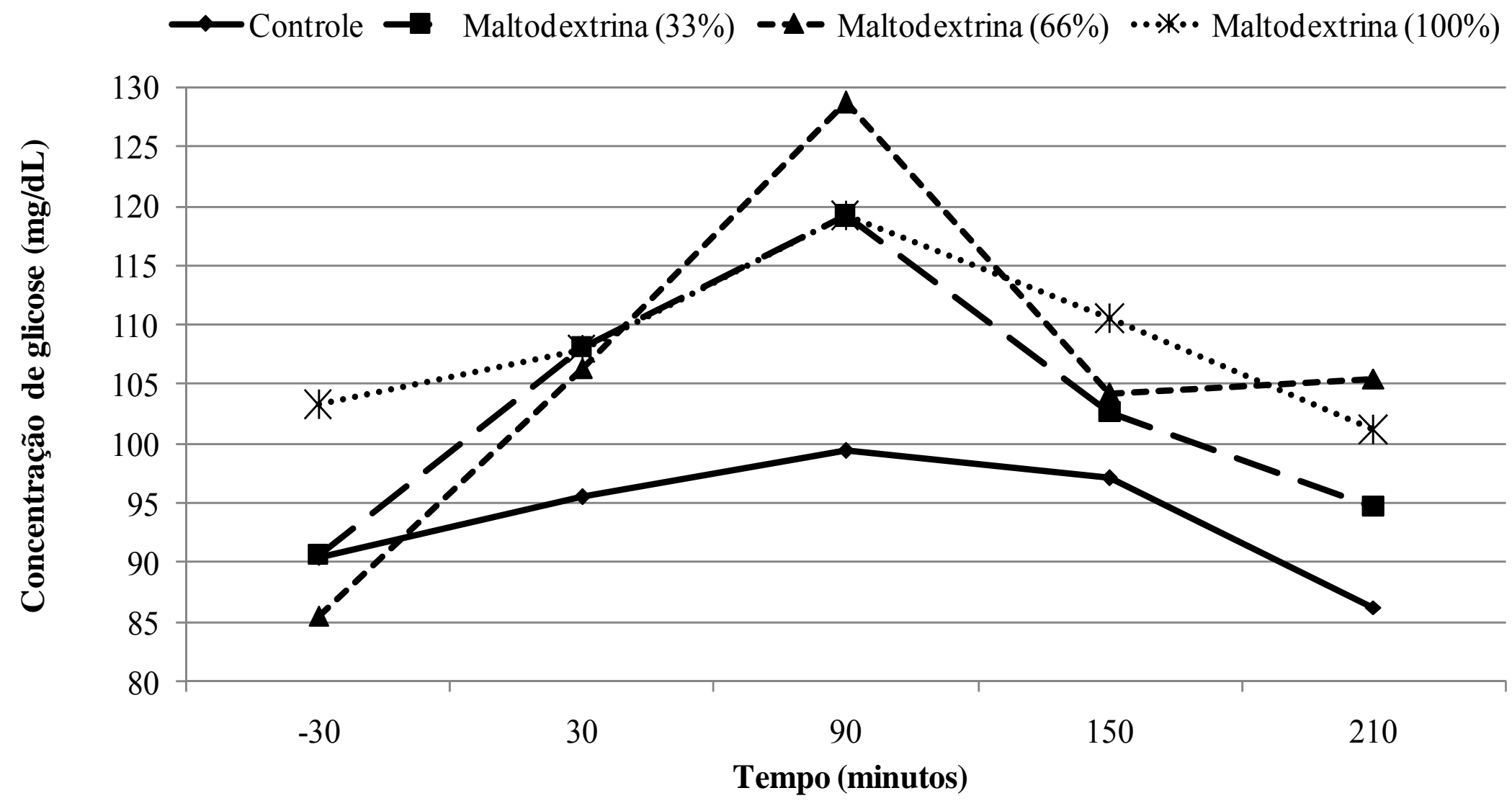

Figura 7- Concentração plasmática de glicose em função do tempo de acordo com as dietas experimentais 
Vervuert et al. (2004) observaram que, 30 a 45 minutos após a alimentação, ocorre significativo aumento nos níveis plasmáticos de glicose e que esses níveis diminuíram para valores basais 150 a 240 minutos após a alimentação. Segundo Healy et al. (1995), eqüinos alimentados com concentrado farelado apresentaram pico de glicose plasmática aos 150 minutos após a ingestão, enquanto naqueles alimentados com concentrado peletizado esse pico ocorreu após 180 minutos, sugerindo que mais glicose foi absorvida da dieta peletizada e comprovando o efeito do processamento.

Um dos efeitos adicionais observados da ingestão de maltodextrina refere-se à elevação dos níveis de glicemia. Essa elevação é imprescindível para o desempenho físico, pois altas concentrações de glicose favorecem a síntese de glicogênio muscular, e uma diminuição nessas concentrações pode levar à fadiga durante a competição (MAMUS et al., 2006).

Quando se comparou os níveis de glicose plasmática dentro de cada tempo de colheita pode se observar diferenças significativas entre as rações experimentais. No entanto não se observou efeito das rações experimentais nos tempos 30 e 150 minutos pós-alimentação (Tabela $8)$. 
Tabela 7- Media, coeficiente de variação (CV), do nível de glicose sanguínea em função das rações experimentais

\begin{tabular}{|c|c|c|c|c|c|c|c|c|c|c|c|c|}
\hline \multirow[t]{3}{*}{ Variaveis } & \multicolumn{4}{|c|}{ Dietas experimentais $^{1}$} & Media & $\mathrm{CV}(\%)$ & \multicolumn{6}{|c|}{ Valores de $\mathrm{P}$} \\
\hline & \multirow[t]{2}{*}{ Controle } & \multicolumn{3}{|c|}{ Maltodextrina } & & & Dieta & Tempo & Int & Linear & Quad & Desvio \\
\hline & & 33 & 66 & 100 & & & & & & & & \\
\hline Glicose (mg/dL) & 93,72 & 103,05 & 106,02 & 108,37 & 102,79 & 17,26 & 0,167 & 0,008 & 0,765 & $0,004^{*}$ & 0,454 & 0,773 \\
\hline Insulina $(\boldsymbol{\mu} \mathrm{UI} / \mathrm{mL})$ & 6,27 & 8,20 & 7,91 & 10,49 & 8,21 & 60,37 & 0,001 & 0,086 & 0,762 & $0,001^{* *}$ & 0,681 & 0,076 \\
\hline
\end{tabular}

${ }^{1} \mathrm{C}=$ Controle $0 \%$ substituição do amido pela maltodextrina no concentrado, 33=33\% substituição do amido pela maltodextrina no concentrado, $66=66 \%$ substituição do amido pela maltodextrina no concentrado, $100=100 \%$ substituição do amido pela maltodextrina no concentrado

${ }^{*}$ GLICOSE $=95,80+0,14 X, \mathrm{R}^{2}=0,42$.

${ }^{* *}$ INSULINA $=6,37+0,037 \mathrm{X}, \mathrm{R}^{2}=0,34$.

Sendo $\mathrm{X}=$ Porcentagem da substituição do amido pela maltodextrina no concentrado. 
Tabela 8- Médias das concentrações plasmáticas de glicose e insulina, em função dos tempos de colheitas, de acordo com as dietas experimentais.

\begin{tabular}{|c|c|c|c|c|c|c|c|}
\hline \multirow{2}{*}{ Variáveis $^{2}$} & \multirow{2}{*}{ Rações $^{1}$} & \multicolumn{5}{|c|}{ Tempo em minutos } & \multirow{2}{*}{ Médias } \\
\hline & & -30 & 30 & 90 & 150 & 210 & \\
\hline \multirow{4}{*}{ Glicose (mg/dL) } & $\mathrm{C}$ & $90,37 \mathrm{AB}$ & 95,5 & 99,37B & 97,12 & $86,25 \mathrm{~B}$ & 93,72 \\
\hline & 33 & $90,62 \mathrm{AB}$ & 108,10 & $119,10 \mathrm{~A}$ & 102,60 & $94,75 \mathrm{AB}$ & 103,05 \\
\hline & 66 & $85,50 \mathrm{~B}$ & 106,30 & $128,60 \mathrm{~A}$ & 104,10 & $105,50 \mathrm{~A}$ & 106,02 \\
\hline & 100 & $103,20 \mathrm{~A}$ & 107,80 & $119,10 \mathrm{~A}$ & 110,50 & $101,10 \mathrm{~A}$ & 108,37 \\
\hline \multirow{4}{*}{ Insulina $(\boldsymbol{\mu} \mathrm{UI} / \mathrm{mL})$} & $\mathrm{C}$ & $2,90 \mathrm{~B}$ & $6,85 \mathrm{~B}$ & $7,82 \mathrm{~B}$ & 8,82 & $4,95 \mathrm{~B}$ & 6,27 \\
\hline & 33 & $4,47 \mathrm{AB}$ & $8,25 \mathrm{AB}$ & $11,15 \mathrm{AB}$ & 8,82 & $8,3 \mathrm{AB}$ & 8,20 \\
\hline & 66 & $2,45 \mathrm{~B}$ & $6,62 \mathrm{~B}$ & $10,8 \mathrm{~B}$ & 9,47 & $10,22 \mathrm{~A}$ & 7,91 \\
\hline & 100 & $7,25 \mathrm{~A}$ & $10,52 \mathrm{~A}$ & $15,15 \mathrm{~A}$ & 8,12 & $11,40 \mathrm{~A}$ & 10,49 \\
\hline
\end{tabular}

$\mathrm{C}=$ Controle $0 \%$ substituição do amido pela maltodextrina no concentrado, $33=33 \%$ substituição do amido pela maltodextrina no concentrado, $66=66 \%$ substituição do amido pela maltodextrina no concentrado, $100=100 \%$ substituição do amido pela maltodextrina no concentrado. ${ }^{2}$ Médias seguidas de letras maiúsculas na coluna se diferenciam $(\mathrm{P}<0,05)$

No tempo -30 de colheita houve uma superioridade do nível de glicose para a ração com substituição de $100 \%$ do amido pela maltodextrina no concentrado em relação às demais. Neste menos tempo se observou menor valor para a ração com substituição de $66 \%$ do amido pela maltodextrina no concentrado.

De mesma forma foi observado um maior valor $(\mathrm{P}<0,05)$ de glicose plasmática para as rações com $66 \%$ de substituição do amido pela maltodextrina nos tempos 90 e 210 minutos, quando se comparou esta ração com a ração controle. Não foi observado diferença $(\mathrm{P}>0,05)$ entre as rações com 33\% e 100\% de substituição do amido pela maltodextrina, os quando comparado a ração com a ração com $66 \%$ de substituição, nos tempos supracitados.

Stull \& Rodiek et al.(1988) avaliaram os níveis plasmáticos de glicose de cavalos quarto de milha recebendo dietas com diferentes proporções de volumoso e concentrado, encontraram um pico de glicose entre os tempos de 3 a 4 horas pós-alimentação, em contrapartida este estudo verificou um pico de glicose 1,5 horas após a alimentação, resultado que confirma a eficácia da maltodextrina em proporcionar uma melhor resposta glicêmica que ouras fontes de carboidratos

Gobesso et al.(2009), trabalharam com 4 eqüinos em um ensaio de resposta glicêmica e insulinêmica, fornecendo dietas com diferentes 4 fontes de amido diferentes, e quando analisaram a resposta glicêmica dentro do mesmo tempo de colheita pós-alimentação 
observaram diferenças $(\mathrm{P}<0,05)$ entre as dietas fornecidas, resultados semelhantes aos encontrados no presente estudo.

Em relação níveis plasmáticos de insulina não foi observado efeito $(\mathrm{P}>0,05)$ de tempo e interação entre a dieta e os tempos de colheita, no entanto foi observado efeito $(\mathrm{P}<0,05)$ de dieta, onde se observou um aumento nos níveis plasmáticos de insulina independentemente do tempo de colheita (Tabela 8).

Em relação à resposta insulinêmica foi observado um comportamento linear $(\mathrm{P}<0,05) \mathrm{em}$ função da substituição do amido pela maltodextrina nos concentrados. Analisando a equação da reta pode se observar que para cada $1 \%$ de substituição do amido pela maltodextrina nos concentrados há um aumento de $6,37 \mu \mathrm{UI} / \mathrm{mL}$ no nível plasmático de insulina. Este comportamento pode ser observado até o tempo de 120 minutos pós-colheita para as rações que tiveram a substituição do amido pela maltodextrina (Figura 8).

Analisando o pico de plasmático de insulina em função das rações experimentais pode se observar que a ração com $100 \%$ de substituição do amido pela maltodextrina apresentou maior pico de glicose no tempo de 90 minutos pós-alimentação, também foi observado que as rações com substituição do amido pela maltodextrina apresentaram uma maior persistência nos níveis plasmáticos de insulina em relação a ração controle (Figura 8).

Quando se comparou os níveis de insulina plasmática dentro de cada tempo de colheita se observou diferenças significativas $(\mathrm{P}<0,05)$ entre as rações experimentais. No entanto não se observou efeito das rações experimentais no tempo 150 minutos pós-alimentação (Tabela 8).

Gordon et al.(2008) realizaram ensaio de resposta insulinêmica com 6 potros quarto de milha avaliando dietas com baixo nível de açúcar e altos níveis de amido, com 3 diferentes fontes de processamento do concentrado pellet $(4 \mathrm{~mm})$, extrusada $(5 \mathrm{~mm})$ e oval $(19 \mathrm{~mm})$, observaram o pico de insulina 2 horas após a alimentação, resultado semelhante ao do presente estudo. No entanto Gobesso et al.(2008); Gobesso et al.(2009), realizando ensaio semelhante ao do presente estudo observaram o pico de insulina entre 3 a 4 horas pós-alimentação.

Foram observados maiores níveis de insulina plasmática para a ração com 100\% de substituição do amido pela maltodextrina nos tempos -30, 30 e 150 minutos pós-alimentação em comparação com as demais experimentais. No tempo de 210 minutos pós-alimentação foram 
observados maiores valores de insulina tanto para a ração com 66 e 100\% de substituição em comparação com as demais rações.

A substituição do amido pela maltodextrina no concentrado proporciona aos animais uma resposta glicêmica e insulinêmica mais consistente, persistente, apresentando picos tanto de glicose como de insulina em um menor tempo, que permite o uso deste aditivo para cavalos em exercícios moderados a intensos em um período de tempo mais prolongado, em relação a outras fonte de amido mais complexas. 


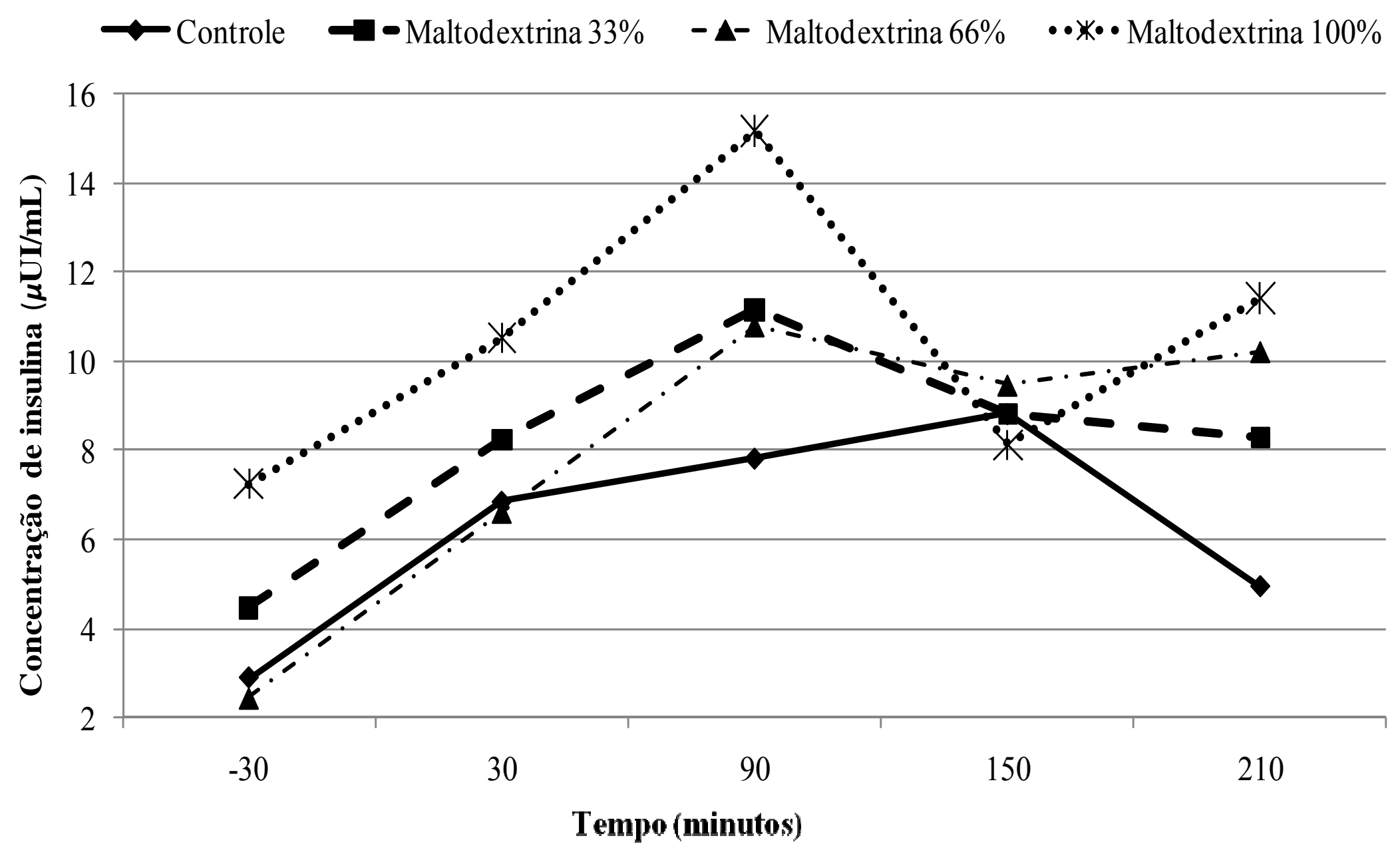

Figura 8 - Níveis plasmáticos de insulina em função das rações experimentais. 


\section{Conclusões}

A substituição do amido pela maltodextrina no concentrado de equinos não alterou a digestibilidade aparente total dos nutrientes.

A substituição do amido pelo maltodextrina apresentou efeito positivo sobre a resposta glicêmica e insulinêmica, apresentando um nível ótimo de inclusão de 77\% na substituição do amido pela maltodextrina tendo um grande potencial para a suplementação de cavalos atletas. 


\section{REFERÊNCIAS}

ALMEIDA, M. I. V.; FERREIRA, W. M.; ALMEIDA, F. Q. Composição química e predição do valor nutritivo de dietas para eqüinos. Revista Brasileira de Zootecnia, v. 28, n. 6, p. 1268-1278, 1999.

AOKI, A. S.; PONTES JR., F. L.; NAVARRO, F.; UCHIDA, M. C.; BACURAU, R. F. P. Suplementação de carboidrato não reverte o efeito deletério do exercício de endurance sobre o subseqüente desempenho de força. Revista Brasileira de Medicina do Esporte, v. 9, n. 5, p. 256-275, 2003.

ARAÚJO, L. D. O. Comparação da digestibilidade aparente em eqüinos submetidos a dieta composta de concentrado e volumosos, fornecidos com diferentes intervalos de tempo. 1992. 7 2p. Dissertação (Mestrado em Zootecnia) - Universidade Federal de Minas Gerais, Belo Horizonte, 1992

BALDISSERA, V. Fisiologia do Exercício para Eqüinos. Caderno Técnico da Escola de Veterinária da UFMG. $\mathrm{n}^{\circ}$ 19. 1997. 39-48 p.

BERGMEYER, H. V. Methods of enzimatic analysis. 2nd ed. NY: Academic Press, 2004. p. 1205-1214.

BURGESS, M. L.; ROBERTSON, R. J.; DAVIS, J. M.; NORRIS, J. M. Failure of low dose carbohydrate feeding to attenuate glucoregulatory hormone responses and improve endurance performance. International Journal of Sports and Nutrition, v. 1, p. 338-352, 1991.

BURGESS, M. L.; ROBERTSON, R. J.; DAVIS, J. M.; NORRIS, J. M. RPE, blood glucose, and carbohydrate oxidation during exercise: effects of glucose feedings. Medicine and Science in Sports and Exercise, v. 23, p. 353-359, 1991. 
CARVALHO, M. A. G. de. Digestibilidade aparente em eqüinos submetidos a três condutas de arrazoamento. 1992. 34 p. Tese (Doutorado) - Escola de Veterinária da Universidade Federal de Minas Gerais, Belo Horizonte, 1992.

COGGAN, A. R. Plasma glucose metabolism during exercise: effect of endurance training in humans. Medicine \& Science in Sports and Exercise, v. 29, n.5, p. 620-627, 1997.

COGGAN, A. R.; COYLE, E. F. Reversal of fatigue during prolonged exercise by carbohydrate infusion or ingestion. Journal of Applied Physiology, v. 63, n. 6, p. 23882395, 1987.

COGGAN, A. R.; SWANSON, S. C. Nutritional manipulations before and during endurance exercise: effects on performance. Medicine \& Science in Sports and Exercise. v. 24, n. 9, p. S331-S335, 1992.

COSTILL, D. L.; HARGREAVES, M. Carbohydrate, nutrition and fatigue. Sports Medicine, v. 13, n. 2, p.86-92, 1992.

COYLE, E. F. M. L. RAUB, R. H.DAVISON, K. E. YOUNG . Muscle glycogen utilization during prolonged strenuous exercise when fed carbohydrate. Journal of Applied Physiology, v. 61, n.1 p. $165-172,1986$.

CYRINO, E. S.; ZUCAS, S. M. Influência da Ingestão de Carboidratos Sobre o Desempenho Físico. Revista de Educação Física UEM, v 3005948 604-25. 10, n. 1, p. 73-79, 1999.

FEBBRAIO, M. A.; CHIU, A.; ANGUS, D. J.; ARKINSTALL, M. J.; HAWLEY, J. A. Effects of carbohydrate ingestion before and during exercise on glucose kinetics and performance. Journal of Applied Physiology, v. 89, p. 2220-2226, 2000.

FRAPE, D. Nutrition y alimentacion del caballo. Zaragoza. Acribia, 1992. 403 p.

GOBESSO, A. A. O. D’AURIA, E.; PREZOTTO, L. D.; RENNÓ, F. P. Substituição de milho por sorgo triturado ou extrusado em dietas para eqüinos. Revista Brasileira de Zootecnia v.37, n. 11, p. 2011-2016, 2008.

GOBESSO, A. A. O.; ETCHICHURY, M.; TOSI, H. Resposta plasmática de glicose e insulina em eqüinos alimentados com diferentes fontes de amido. Brazilian. Journal of. Veterinaty Research and Animal Science, v. 46, n. 4, p. 324-331, 2009.

GONÇALVES, L. C.; REZENDE, A. S. C.; CARVALHO, M. A. G. Digestibilidade aparente em eqüídeos submetidos a três condutas de arraçoamento. I. Matéria seca, proteína bruta e 
energia bruta. Arquivo Brasileiro de Medicina Veterinária e Zootecnia, v. 50, n. 4, p. 421427, 1998.

GORDON, M. E. JERINA, M. L. RAUB, R. H.DAVISON, K. E. YOUNG, J. K. The effects of feed form on consumption time and glucose and insulin response to a concentrate meal in equine. Journal of Equine Veterinary Science v.28, n 5, p289-294, 2008

GRAY G.M. Starch digestion and absorption in nonruminants. Journal of Nutrition, v. 122 n. 1, p. 172-177, 1992.

GUERRA, P.; MEDEIROS, S.A.F. Estudo mostra que mercado eqüino gera R\$ 7,3 bilhões por ano. Confederação da Agricultura e Pecuária do Brasil. (s/l), 2006. Disponível em: $<$ http://www.cna.org.br/site/noticia.php?n=13894>. Acesso em: 08 set. 2008.

GUEZENNEC, C. Oxidation rates, complex carbohydrates and exercise. Sports Medicine, v. 19 p. 365-372 1995.

GUIMARÃES, J.L.; ADELL, E.A.A. Estrutura e bioquímica do músculo. Apostila do Laboratório de Carnes. Unicamp, 1995. 34 p.

HARGER-DOMITROVICH, S. G.; MCCLAUGHRY, A. E.; GASKILL, S. E.; RUBY, B. C. exogenous carbohydrate spares muscle glycogen in men and women during $10 \mathrm{~h}$ of exercise. Medicine. Science Sports Exerc v. 39, n. 12, p-125 135 , 2007.

HEALY, H. P.; SICILIANO, P. D.; LAWRENCE, L. M. Effect of concentrate form on blood and gastric fluid variables in ponies. Journal of Equine Nutrition, v. 15, n. 10, p. 423-428, 1995.

HENSON, D. A.; DAVIS, J. M.; BUTTERWORTH, D. E. Effects of carbohydrate ingestion and hormonal responses on ratings of perceived exertion during prolonged cycling and running. Europen 3005948 604-25 v. 80, p. 92-99, 1999.

HINTZ, H. F. Nutrition del caballo. In: EVANS, J. W. El Caballo. Zaragoza Acribia, 1979. pt. 3, p. 233-247.

HODGSON, D.R.; ROSE, R.J. The Athletic Horse: Principles and Practice of Equine Sports Medicine. Philadelphia: Saunders, 1994. 497 p.

JHONSON, N. A.; STANNARD, S. R.; THOMPSON, M. Triglyceride and glycogen in endurance exercise: implications for performance. Sports Medicine v. 34, n. 3, p. 151-164, 2004. 
KIENZLE, E. Small intestinal digestion of starch in the horse. R. Méd. Vét., v. 145, n. 3, p. 199-204, 1994b

KOHNKE, J. R. Feeding and nutrition. Birubi Pacific: The making of a Champion, 1992, $197 \mathrm{p}$.

LANCHA JR., A. H. Nutrição e metabolismo aplicados à atividade motora. São Paulo: Atheneu, 2002.

LEE, J. S.; BRUCE, C. R.; TUNSTALL, R. J.; CAMERON-SMITH, D.; HÜGEL, H.; HAWLEY, J. A. Interation of exercise and dieta on GLUT-4 protein and gene expression in type I e type II rat skeletal muscle. Acta Physiologica Scandinavica, v. 175, p. 37-44, 2002.

LEHNINGER, A.L.; NELSON, D.L.; COX, M.M. Princípios de Bioquímica. São Paulo: Sarvier, 2000. $552-557 \mathrm{p}$.

MAMUS, R.; SANTOS, M. G. Efeitos bioquímicos da suplementação de carboidratos após uma competição simulada de Short Duathlon Terrestre. Revista Portuguesa de Ciências do Desporto, v. 6, n. 1, p25 -42, 2006.

MANZANO, A.; MANZANO, M. F. F. L. Utilização do guandu (Caianus caian (L) Millsp) na alimentação de eqüinos. Revista Brasileira de Zootecnia, v. 19, n. 6, p. 459-468, 1990

MASSEY, K. J.; POTTER, G. D. Prececal, postileal and total tract starch digestion in ponies fed at varying intervals, In EQUINE NUTRITION AND PHISIOLOGY SYMPOSIUM, 9., 1985, Michigan. Proceedings... Michigan, 1985. p.289-322.

MCARDLE, W. D.; KATCH, F. I.; KATCH, V. L. Nutrição para o desporto e o exercício. Rio de Janeiro: Guanabara Koogan, 2001.

MEYER, H. Alimentação de cavalos. São Paulo: Livraria Varela, 1995. 303 p.

MILLARD-STAFFORD, M.; ROSSKOPF, L. B.; SNOW, T. K.; HINSON, B. T. Water versus carbohydrate-electrolyte ingestion before and during a $15 \mathrm{~km}$ run in the health. International Journal of Sport and Nutrition, v. 7, n. 1, p. 26-38, 1997.

MOORE, G. R. P.; CANTO, L. R.; AMANTE, E. R.; SOLDI, V. Cassava and corn starch in maltodextrin production. Química Nova, v. 28, n. 4, p.34- 38, 2005. 
MORGADO, E. S.; ALMEIDA, F. Q.; SILVA, V. P.; GOMES, A. V. C.; GALZERANO, L. VENTURA, H. T.; RODRIGUES, L. M. Digestão dos carboidratos de alimentos volumosos em eqüinos. Revista Braseleira de Zootecnia, v. 38, n. 1, p. 75-81, 2009.

MORGADO, E.; GALZERANO, L. Utilização de Óleo em Dietas para Eqüinos. Revista Eletrônica de Veterinária. vol. 2, $\mathrm{n}^{\mathrm{o}} \quad 10.2006 .2$ Disponível em: $<$ http://www.veterinaria.org/revistas/redvet/n101006.html>. Acesso em: 21 out. 2008.

MURRAY, R.; BARTOLI, W. P.; EDDY, D. E.; HORN, M. K. Physiological and performance responses to nicotinic-acid ingestion during exercise. Medicine and Science in Sports and Exercise, v. 27, p. 1057-1062, 1995.

MURRAY, R.; PAUL, G. L.; SEIFERT, J. G.; EDDY, D. E. Responses to varying rats of carbohydrate ingestion during exercise. Medicine and Science in Sports and Exercise v. 23, p. 713-718, 1991.

NIEMAN, D. C.; AHLE, J. C.; HENSON, D. A.; WARREN, B. J.; SUTTLES, J.; DAVIS, J. M.; BUCKELEY, K. S.; SIMANDLE, S.; BUTTERWORTH, D. E.; FAGOAGA, O. R.; NEHLSEN-CANNARELLA, S. L. Indomethacin does not alter natural killer cell response to 2,5 h of running. Journal of Applied Physiology, v. 79, p. 748-755, 1995.

NIEMAN, D. C.; DAVIS, J. M.; HENSON, D. A.; WALBERG-RANKIN, J.; SHUTE, M.; DUMKE, C. L.; VINCI, D. M.; CARSON, J. A.; BROWN, A.; LEE, W. J.; McANULTY, S. R.; MCANULTY, L. S.. Carbohydrate ingestion influences skeletal muscle cytokine mRNA and plasma cytokine levels after a 3-h run. Journal of Applied Physiology v. 94, p. 19171925, 2003.

NIEMAN, D. C.; FAGOAGA, O. R.; BUTTERWORTH, D. E.; WARREN, B. J.; UTTER, A.; DAVIS, J. M.; HENSON, D. A.; NEHLSEN-CANNARELLA, S. L. Carbohydrate supplementation affects blood granulocyte and monocyte trafficking but not function after 2,5 h or running. American Journal Clinical Nutrition, v. 66, p. 153-159, 1997.

NIEMAN, D. C.; HENSON, D. A.; SMITH, L. L.; UTTER, A. C.; VINCI, D. M.; DAVIS, J. M.; KAMINSKY, D. E.; SHUTE, M. Cytokine changes after a marathon race. Journal of Applied Physiology, v. 91, p. 109-114, 2001.

NUTRIENTS REQUIMENTS OF HORSE. 5. ed. Washington: National Academy of Science, 1989. $100 \mathrm{p}$.

NUTRIENTS REQUIMENTS OF HORSE. 5. ed. Washington: National Academy of Science, 2007. 200 p. 
OLIVEIRA, K.; FURTADO, C. E.; GRAÇA, E. P. Desempenho e parâmetros sangüíneos de equinos em crescimento submetidos a dietas com diferentes níveis de farelo de canola. Revista Brasileira de Zootecnia, v. 30, n. 1, p. 174-180, 2001.

PARKER, R. Equine science. London: Delmarell, 1998. 660p.

PEREIRA, J. C.; CARMO, M. B.; MOTTA, V. A. F. L. Feno de aveia associado ao concentrado em diferentes proporções na alimentação de eqüinos. Revista Brasileira de Zootecnia, v. 18, n. 5, p. 359-366, 1989.

PEREIRA, J. R. A.; ROSSI JUNIOR,R.L. Manual prático de avaliação nutricional dos alimentos. Piracibaca: Fundação de Estudos Agrários Luiz de Queiroz - FEALQ, 1998. p. 19-20,

POTTER, G. D.; ARNOLD, F. F.; HOUSEHOLDER, D. D.; HANSEN, D. H. Digestion of starch in the small or large intestine of the equine: Pferdeheilkunde, v. 1, p. 107-111, 1992. Trabalho apresentado no 1st European Conference on Horse Nutrition, 1992.

PUOLI FILHO, J. N. P. Parâmetros Fisiológicos do desempenho de cavalos de alta performance hidratados voluntariamente com água ou solução isotônica contendo carboidrato. São Paulo, 2004. 2p. Dissertação (Doutorado em Ciências). Escola Paulista de Medicina, Universidade Federal de São Paulo.

QUADROS, J. B. S.; FURTADO, A. E.; BARBOSA, E. D.; ANDRADE, M. B.; TREVISAN, A. G. Digestibilidade aparente e desenvolvimento de eqüinos em crescimento submetidos a dietas compostas por diferentes níveis de substituição do feno de tifton 85 pela casca de soja. Revista Braseleira de Zootecnia, v. 33, n. 3, p. 564-574, 2004.

RADICKE, S.; KIENZLE, E.; MEYER, H. Preileal apparent digestibility of oats and corn starch and consequences for cecal metabolism. In: EQUINE NUTRITION AND PHYSIOLOGY SYMPOSIUM, 12., 1991, Calgary. Proceedings... Calgary: Equine Nutrition and Physiology Society, 1991.p. 43.

RANKIN, J. W. Glycemic index and exercise metabolism. Sports Science Exchange, v. 10, n. 1, p154-164 1997.

RUFFO, A. M. Efeitos da Suplementação de diferentes concentrações de maltodextrina em ratos submetidos a exercício contínuo e prolongado. Curitiba: [s.n.], 2004.

SALES, R.P.; MINÉ, C.E.C.; FRANCO, A.D.; RODRIGUES, E.L.; PELÓGIA, N.C.C.; SILVA, R.S.S.; COGO, J.C.; MARTINS, R.A.B.L.; OSORIO, R.L.; RIBEIRO, W. Efeitos da Suplementação 
Aguda de Aspartato de Arginina na Fadiga Muscular em Voluntários Treinados. Revista Brasileira de Medicina do Esporte. vol. 11, nº 6. Niterói, 2005.

SANTOS, C. P.; FURTADO, C. E.; JOBIM, C. C. Avaliação da silagem de grãos úmidos de milho na alimentação de eqüinos em crescimento: valor nutricional e desempenho. Revista Brasileira de Zootecnia, v. 31, n. 3, p. 1214-1222, 2002.

SAPATA, B. S.; FAYH, A. P.; OLIVEIRA, A. R. Efeitos do consumo prévio de carboidratos sobre a resposta glicêmica e desempenho. Revista Brasileira de Medicina do Esporte, v. 12, v. 4, p.256-268, 2006.

SHEPHARD, R. J.; SHEK, P. N. Heavy exercise, nutrition and immune function: is there a connection? International Journal of Sports Medicine v. 16, p. 491-497, 1995.

SILVA, A. M. R. BERTO, D. A.; LIMA, J. L. M. M.; WECHSLER, F. S.; PADILHA, P. M. CASTRO,V. S. Valor nutricional e viabilidade econômica de rações suplementadas com maltodextrina e acidificante para leitões desmamados. Revista Brasileira de Zootecnia, v. 37, n.2, p.286-295, 2008.

SILVA, A. M. R.; BERTO, D. A.; LIMA, G. J. M. M.; WECHLER, F. S.; PADILHA, P. M.; CASTRO, V. S. Valor nutricional e viabilidade econômica de rações suplementadas com maltodextrina e acidificante para leitões desmamados. Revista Brasileira de Zootecnia, v. 37, n. 2, p. 95-105, 2008.

SILVA, D. J. Análise de alimentos (Métodos Químicos e Biológicos). Viçosa: UFV, Imprensa Universitária, 1990.165 p.

SILVA, L.Q.P. Fisiologia do Exercício no Cavalo Atleta. 2005. 50 f. Monografia. Faculdade de Medicina Veterinária e Zootecnia, Universidade Estadual Paulista. Jaboticabal.

SMITH, G. J. A.; GRAY, A. B.; PYNE, D. B.; BAKER, M. S.; TELFORD, R. D.; WEIDEMANN, M. J. Moderate exercise triggers both priming and activation of neutrophil subpopulations. American Journal of Physiology, v. 270, p. R838-R845, 1996.

SMITH, G. J.; RHODES, E. C.; LANGILL, R. H. The effect of pre-exercise glucose ingestion on performance during prolonged swimming. International Journal of Sport Nutrition \& Exercise Metabolism, v. 12, n. 2, p. 136-144, 2002.

SNOW, D. H. Exercise and Training. In: HICKMAN, J. Horse management. 2. ed. London: Academic Press, 1987. chap. 9, p. 380-1. 
STULL, C. L.; RODIEK, A. V. Responses of blood glucose, insulin and cortisol concentrations to common equine diets. The Journal of Nutrition, v. 118, n. 2, p. 206-213, 1988.

THOMASSIAN, A. Enfermidades dos Cavalos. São Paulo: Varela, 2005. 81 - 94 p.

THUMA, J. R.; GILDERS, R.; VERDUN, M.; LOUCKS, A. B. Circadian rhythm of cortisol confounds cortisol responses to exercise: implications for future research. Journal of Applied Physiology, v. 78, p. 657-1664, 1995.

TONKK, D. B. Quality control in clinical laboratories, diagnostic reagents division. Canada: Searborough, 1972.

UTERR, A. C.; KANG, J.; NIEMAN, D. C.; WILLIAMS, F.; ROBERTSON, R. J.; UTERR, A. C.; KANG, J.; ROBERTSON, R. J.; NIEMAN, D. C.; CHALOUPKA, E. D.; SUMINSKI, R. R.; PICCINNI, C. R. Effect of carbohydrate ingestion on ratings of 62 perceived exertion during a marathon. Medicine and Science in Sports and Exercise, v. 34, n. 11, p. 17791784, 2002.

VAN DER VUSSE, G. J.; RENEMAN, R. S. Lipid metabolism in muscle. In: ROWELL, L. B.;SHEPHERD, J. T. (Ed). Handbook of physiology. Oxford: Oxford University Press, 1996. sect. 12, p. $952-994$.

VERVUERT, I.; COENEN, M.; BOTHE, C. Effects of corn processing on the glycaemic and insulinaemic responses in horses. Journal Animal Physiology and Animal Nutrition, v. 88, p. 348-355, 2004.

WEBER, E.; EHRLEIN, H. J. Glucose and maltodextrin in enteral diets have different effects on jejunal absorption of nutrients, sodium and water and on flow rate in mini pigs. Deutsche Tierarztliche Wochenschrift, v. 105, n. 12, p. 446-449, 1998. (Abstract).

WHITAKER, H. M. A.; CARVALHO, R. L. Substituição do milho pelo sorgo em rações para eqüinos. Revista Brasileira de Zootecnia, v. 26, n. 1, p. 139-143, 1997.

WILMORE, J. H.; COSTILL, D. L. Fisiologia do esporte e do exercício. 2 ed. São Paulo: Manole, 2001.

WOLTER, R. Le Cheval, la digestion chez le cheval. In: JOURNÉES DE BRESSIER DE THEIX, 12., 1981, Paris. p. 186-194. 
YALOW, R. S.; BERSON, S. A. Immunoassay of endogenous plasma insulin in a man. Journal of Clinical Investigation, v. 39, n. 7, p. 1157-1175, 1960.

YU P.; HUBER, J. T.; THEURER, C. B.; CHEN, K. H.; NUSSIO, L.G.; WU, Z. Effect of steam-flaked or steam-rolled corn with or without Aspergillus oryzae in the diet on performance of dairy cows fed during hot weather Journal of Dairy Science, v. 80, n. 12, p. 3293-3297, 1997.

ZANKER, C. L.; SWAINE, I. L.; CASTELL, L. M.; NEWSHOLME, E. A. Responses of plasma glutamine, free tryptophan and branchedchain amino acids to prolonged exercise after a regime designed to reduce muscle glycogen. Europen Journal of Applied Physiology, v. 75, p. 543-548, 1997. 